\title{
The World Income Distribution: The Effects of International Unbundling of Production*
}

\author{
Sergi Basco \\ Universidad Carlos III \\ Martí Mestieri \\ Toulouse School of Economics
}

November 2014

\begin{abstract}
We build a dynamic trade model to study how international unbundling of production and the emergence of global supply chains affect the world income distribution. We consider a world where countries only differ in their productivity. The level of productivity determines the number of varieties a country produces. To manufacture each variety a bundle of intermediates, which require capital and labor in different proportions, needs to be assembled. We characterize two trade regimes: (i) trade only in varieties and (ii) trade in both varieties and intermediates (unbundling). We show that unbundling of production generates income divergence among ex-ante identical countries (symmetry breaking). With heterogeneous countries, it increases top-bottom inequality and it has non-monotonic effects on the world income distribution (it reduces relatively more the income share of middle-productivity countries). Unbundling of production also increases within-country inequality in all countries. We also show that when the South joins the global supply chain, the income share of all northern and the most productive southern countries increase, at the expense of the least productive countries. In addition, we find that the effect of a labor-saving technology, computerization, depends on the trade regime. Without unbundling, computerization has no effect on the world income distribution. With unbundling, computerization raises world inequality. Finally, we show that technology diffusion leads to income convergence under both trade regimes. However, with unbundling of production more low-productivity countries benefit from technological catch-up.
\end{abstract}

Keywords: World Income Distribution, Symmetry Breaking, Global Supply Chains.

JEL Classification: F12, F43, O11, 019, 040.

${ }^{*}$ We thank Daron Acemoglu, Jaume Ventura and seminar participants at Calgary, CEMFI, CEPR-ESSIM, Nottingham, Stanford and UC3M for useful comments and suggestions. We thank Shekhar Tomar for his excellent research assistance. Basco acknoweldges financial support from the Spanish Ministry of Science and Innovation (ECO2011-27014). Mestieri thanks the Agence Nationale de la Recherche for their generous financial support. E-mails: sergi.basco@gmail.com, marti.mestieri@tse-fr.eu. 


\section{Introduction}

One of the most remarkable facts in international trade in the last twenty-five years has been the "unbundling" of production (Baldwin, 2012). Before the 1990s, the production process was much less fragmented across the globe. The unbundling of production has made possible the emergence of "global supply chains," whereby the production of a significant fraction of the intermediate inputs required to manufacture goods is located in different countries. As a result, countries can now also specialize in different stages of the global supply chain. A paradigmatic example of this fragmentation of production is the iPod, which is designed in the United States and assembled in China from several hundred components and parts that are sourced from around the world (Dedrick et al., 2010).

Figure 1 provides new evidence consistent with this unbundling of production. It reports the ratio of the value of world exported intermediates to final goods. Before the mid-1980s this ratio was about .5, which means that for each dollar of intermediate exported there were two dollars of final goods exported. After the 1990s this ratio sharply increased and it has converged to around .8. Therefore, trade in intermediates has grown much more than trade in final goods. These findings are consistent with recent empirical work on the global supply chain. For example, Antràs (2014) shows that the average upstreamness of world exports has increased, which suggests that trade in inputs has become more important over time. Similarly, Johnson (2014) documents that the ratio of value-added to gross-value of exports fell in early 1990s, which is mostly explained by increased offshoring within manufacturing. ${ }^{1}$

Trade affects the income and economic growth of countries. ${ }^{2}$ A vast and rich literature has studied the effects of trade in goods. However, the trade literature has been mostly silent about the distinctive long-run effects of trade in intermediates. ${ }^{3}$ This paper contributes to filling this gap by providing a theory of how the unbundling of production changes the world income distribution.

The key novel aspect of our theory is the introduction of intermediates that are heterogeneous in their capital-intensity. In our framework, the unbundling of production leads countries to sort in the production of intermediates according to their productivity levels. High-productivity countries sort into the production of capital-intensive intermediates. This prediction is supported by the data (see Table 1) and it is quantitatively important. ${ }^{4}$ Note

\footnotetext{
${ }^{1}$ Hummels et al. (2001) also document the emergence of global supply chains, which they refer as vertical specialization, whereby countries specialize in the production of different sets of intermediate inputs. Hanson et al. (2005) show that a sizeable part of this intermediate trade involves multinational firms.

${ }^{2}$ See, for example, Grossman and Helpman (1993) and Ventura (2005) for an overview of the channels through which trade affects economic growth.

${ }^{3}$ One exception is Rodríguez-Clare (2010), which emphasizes the effects of offshoring on the allocation of labor to innovation.

${ }^{4} \mathrm{We}$ find that, if the productivity of a country moved from the 25 th to the 75 th percentile, the rise in the value of exports of intermediates in the 75 th percentile of capital-intensity would be $40 \%$ larger than the increase in the 25 th percentile.
} 
Figure 1: Ratio of Value of Exported Intermediates to Final Goods.

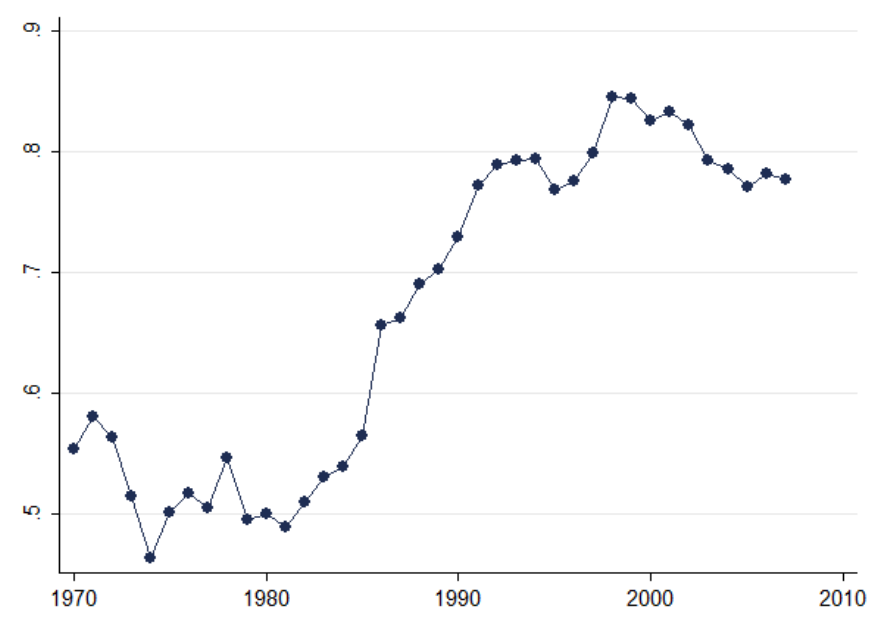

Source: Feenstra World Trade Database. To classify goods as intermediates, we use the end-use classification of Feenstra and Jensen (2012). Final goods also include commodities.

also that this is consistent with the existing empirical literature (e.g., Schott, 2004). ${ }^{5}$

We show that unbundling of production gives rise to income differences among ex-ante identical countries. For heterogeneous countries, we find that unbundling generates nonmonotonic changes in the world income distribution: top-bottom inequality increases and the income share of the most productive countries rises mostly at the expense of middleproductivity countries. It also increases within-country inequality for all countries. These predictions are broadly consistent with the evolution of the world income distribution over the last 25 years.

Our model features a large number of countries, which only differ in their productivity. Each country produces a certain number of varieties. These varieties are differentiated by origin (Armington assumption). ${ }^{6}$ In order to produce a variety, a bundle of intermediates needs to be assembled. Each of these intermediates requires capital and labor in different proportions. As it is standard in the trade literature, we assume that neither labor nor capital are internationally mobile.

Intermediates differ in their capital-intensity requirements to be produced, while all varieties are produced with the same technology. This assumption allows us to highlight the role of heterogeneity in capital-intensity of intermediates. In fact, the dispersion in capital-intensity is larger for more disaggregated goods. Using the direct requirements U.S. input-output table, we show in Figure 7 and Table A.1 that the dispersion in capital-intensity at 6-digit NAICS

\footnotetext{
${ }^{5}$ See also Baxter and Kouparitsas (2003), Hanson (2012) and Schott (2003a,b) for similar findings.

${ }^{6}$ In the baseline model we assume that each country produces an exogenous number of varieties which is proportional to the productivity of the country. Online Appendix C provides an exact microfoundation to the exogenous number of varieties that we postulate in the baseline model.
} 
Figure 2: Market Structure for the 2-country, 2-varieties case

(a) Without Unbundling

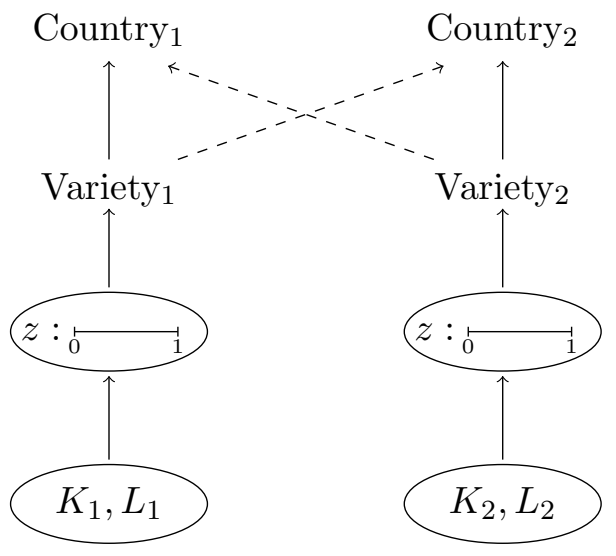

(b) With Unbundling

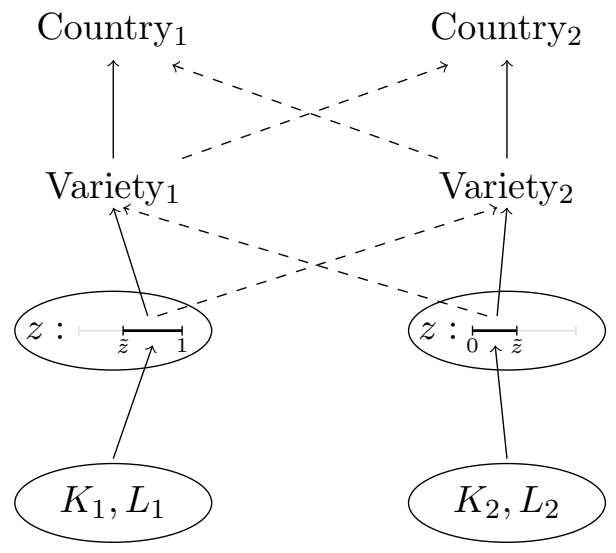

Note: Figure represents the market structure for two countries and two varieties under the two different trade regimes. Dashed lines indicate trade flows.

level (which we interpret as intermediates) is larger than at 3-digit NAICS level (varieties). Therefore, our formulation is an extreme representation of this fact.

We start characterizing the equilibrium without unbundling. When only trade in varieties is possible, each country needs to produce all the required intermediates within its boundaries. Once the intermediates are manufactured and bundled to produce the varieties, these varieties are traded. The structure of this economy is summarized in Figure 2a for a two-country twovariety case. We show that the country's share of world income is determined by the share of varieties the country produces, which is proportional to its productivity. For example, if a country is twice as productive as another country, its share of world income is twice the share of the other country.

The world income distribution changes with unbundling. When intermediates can be offshored, the producer of a variety does not need to purchase all intermediates at home. Rather, it can import intermediates from the cheapest producer in the world. Therefore, the location of intermediates becomes endogenous. The structure of this economy is illustrated in Figure 2b. We show that the most productive countries have comparative advantage and specialize in capital-intensive intermediates. This endogenous selection of intermediates is important because it determines the relative income of each country in the new steady-state. We show that the world income share is determined by the mass of intermediates that a country produces and their relative capital-intensity.

The first main result of the paper is that unbundling of production generates symmetry breaking of ex-ante identical countries. To gain intuition into this result, we first consider a two-country world. In the equilibrium without unbundling, the two countries have the same 
income share, as they produce the same amount of varieties. This symmetric equilibrium is unstable when there is unbundling of production. To understand this result, let us assume that the first country is slightly more productive than the second one. It implies that the first country has a slight comparative advantage in capital-intensive intermediates and, thus, it specializes in more capital-intensive intermediates. By producing more capital-intensive intermediates, it accumulates more capital, thereby reinforcing the initial comparative advantage in capital-intensive intermediates. This process continues over time and the two countries end up with very different stocks of capital in the new steady-state. We show that this argument extends to an arbitrary number of ex-ante identical countries. We also show that unbundling, by changing the relative demand of capital, generates within-country inequality.

Our second main result characterizes the long-run change in the world income distribution with heterogeneous countries. We show that top-bottom inequality rises with unbundling: the world income share increases in high-productivity countries, while it declines in the rest. Moreover, this change is non-monotonic: the largest fall in income share is in middle-productivity countries and the largest rise is in the most productive country. Without unbundling, the stock of capital is determined by the number of varieties that a country produces. In contrast, with unbundling, the number of varieties becomes irrelevant and the stock of capital only depends on the intermediates in which the country specializes. The most productive country gains the most because it specializes in the most capital-intensive intermediates. Middle-productivity countries lose because they produce a sizeable amount of varieties, thereby accumulating a substantial amount of capital in the equilibrium without unbundling. However, when there is unbundling, they specialize in relatively low-capital-inensive intermediates and, thus, end up with less capital. In other words, there is a large mismatch between the capital accumulated during the equilibrium without unbundling and the capital needed to produce the equilibrium mass of intermediates with unbundling. Finally, we also show that unbundling, by sorting countries in the production of different intermediates, increases within-country inequality in all countries.

In addition to analyzing and comparing the equilibria with and without unbundling, our model is helpful to understand other substantial changes that have occurred in the process of unbundling. An important fact in international trade is the increasingly important role of emerging economies. For example, the share of world trade in developing Asia has increased from less than $15 \%$ in the early 1990 s to $35 \%$ in 2011 . It has been argued that unbundling of production explains the increase in the volume of trade in emerging economies (see, for example, Baldwin, 2012). Figure 4 shows that most of the growth of world trade in intermediates has come from emerging countries. Motivated by this evidence, we study how the world income distribution changes when the South joins the global supply chain. To be precise, we analyze the effect of southern countries participating in intermediates trade in a world where all countries previously traded varieties but only northern countries traded intermediates. 
We show that the income share increases in all northern countries and the most productive southern countries, while it declines in the rest of southern countries. Northern countries increase their income share the most because they can specialize in more capital-intensive intermediates and sell them to a larger market. For southern countries, the income share only raises in those that are productive enough to "climb up the supply chain" and specialize in relatively capital-intensive intermediates.

We also use our framework to study the effect of a labor-saving technology: computerization. Computerization (or, more broadly, the Information Technologies revolution) is one important factor behind the surge of the unbundling of production. ${ }^{7}$ Autor et al. (2003) among others have also emphasized the effects of computerization on the relative demand for labor and on the income distribution within countries. We introduce computerization into the model as a technological shift that reduces the relative demand of labor-intensive intermediates. We show that the effect of computerization depends on the trade regime. Without unbundling, computerization does not change the world income distribution. In contrast, with unbundling, computerization raises inequality. The intuition is that computerization changes the selection of intermediates. All countries specialize in more capital-intensive intermediates, thus, the average intermediate produced in each country is more capital-intensive. However, this change in the trade pattern disproportionately favors the most productive countries, which exacerbates income inequality. We also show that computerization raises the capital income share in both trade regimes.

Finally, we analyze how the diffusion of technology changes the world income distribution. In our baseline model we assume that productivity is exogenous and constant. However, in practice, technology diffuses over time and low-productivity countries learn about innovations done by the countries in the technological frontier. We show that diffusion of technology always leads to convergence of income. However, for a given amount of technology diffusion, the mass of low-productivity countries increasing their income share is larger with unbundling.

Related Literature. This paper relates to different strands of the literature on growth, trade and offshoring. There exist a large number of models that study the interaction between economic growth and trade. Our model structure for production of varieties and final good is similar to Acemoglu and Ventura (2002). The most important difference is that we introduce an additional layer of intermediates in the production process. This allows us to study the effect of unbundling on the world income distribution. In contrast to Acemoglu and Ventura (2002), we do not have long-run growth in our model because we have a collection of CobbDouglas countries instead of their AK countries. ${ }^{8}$

\footnotetext{
${ }^{7}$ See, for example, Basco and Mestieri (2013) and the references therein.

${ }^{8}$ Other papers that study how trade in goods affect economic growth include Ventura (1997), Bajona and Kehoe (2010), Baxter (1992), Cunat and Maffezzoli (2004) and Deardorff (2001b). These papers make different assumptions on the number of goods and whether factor prices equalize. However, they do not consider
} 
There exists a growing literature analyzing the unbundling of production and its effects on the pattern of specialization and the wealth of nations. For example, Baldwin and Venables (2013), Baldwin and Robert-Nicoud (2014) and Grossman and Rossi-Hansberg (2008) revisit the standard trade theorems in the presence of trade in intermediates. We model the production process as a sequential process in which intermediates are first produced and then used to assemble each variety. This is similar to, among others, Antràs and Chor (2013), Caliendo and Parro (2012), Costinot et al. (2013), Deardorff (1998, 2001a) and Kohler (2004).Differently from these papers, we build a dynamic trade model and derive our main results from the interaction between the sorting of countries across intermediates of different capital-intensity and capital accumulation.

From a theoretical standpoint, as pointed out by Ethier (1984) and Costinot and Vogel (2010), general equilibrium models with an arbitrary number of countries and goods seldom provide tractable results. Our model provides a framework that accommodates a substantial amount of heterogeneity and still delivers sharp characterizations and comparative statics results. There are two main sources of heterogeneity in our model. First, countries differ in their aggregate productivity, a Ricardian feature. Second, intermediates are heterogeneous in their capital-intensity, a Heckscher-Ohlin feature. We contribute to the dynamic Heckscher-Ohlin literature by showing how the presence of a continuum of traded goods with heterogeneous capital intensities generates a unique steady-state world income distribution (even when differences in productivity across countries are absent). This prediction is in contrast with the case of a finite number of traded goods (e.g., Bajona and Kehoe, 2010 and Caliendo, 2011). In terms of techniques, the characterization of the unbundling equilibrium relies in solving for the equilibrium assignment in a similar manner as in Matsuyama (2013). As our production functions are not linear in the factors of production, we cannot rely on the Ricardo-Roy assignment literature (e.g., Costinot and Vogel, 2010).

In our model, unbundling of production generates symmetry breaking of ex-ante identical countries. In this sense, it is related to, for example, Krugman and Venables (1995) and Matsuyama (2004, 2013). However, our mechanism is different because it does not rely on increasing returns or credit market imperfections. Matsuyama (2013) emphasizes that the share of non-traded services is heterogeneous across varieties. With increasing returns in the production of these non-traded services, this generates a two-way feedback loop that yields symmetry breaking. In our model, similar countries become different with unbundling of production because they specialize in different intermediates, which differ in capital-intensity and this triggers different incentives to accumulate capital across countries. Our framework shows that the emergence of symmetry breaking is linked to the unbundling of production, rather than the fact that countries trade. Thus, in contrast to previous studies, we highlight

trade in intermediates. Yi (2003) calibrates a two-country two-stages Ricardian model to show that vertical specialization is needed to explain how small trade cost reductions resulted in the observed growth in exports. 
the dynamic effects of countries specializing in the production of goods with heterogenous capital-intensities.

The rest of the paper is organized as follows. Section 2 presents the model and characterizes the equilibria with and without unbundling. The main results of the paper comparing the world income distribution with and without unbundling are derived in Section 3. In Section 4.1, we analyze the empirically relevant case in which southern countries join the global supply chain. Section 4.2 analyzes the effects of a labor-saving technology, computerization. Section 4.3 analyzes technology diffusion under the two trade regimes and Section 5 concludes. All proofs can be found in the Online Appendix.

\section{The Model}

This section presents the baseline model and characterizes the steady-state equilibrium without unbundling (when only trade in varieties is possible) and the equilibrium with unbundling (when trade in both varieties and intermediates is possible).

We consider a world economy with $J$ countries, indexed by $j=1, \ldots, J$. Countries only differ in the level of productivity $\theta_{j}$. Without loss of generality, we order countries such that $\theta_{1} \geq \theta_{2} \geq \ldots \geq \theta_{J}$. There is a mass of varieties indexed by $v \in[0, N]$. There is one final good used for consumption and investment. There is no trade in final goods or assets.

All countries admit a representative consumer with utility

$$
\int_{0}^{\infty} e^{-\rho t} \ln c_{j}(t) d t
$$

where $c_{j}(t)$ is consumption in country $j$ at time $t$. Each country $j$ is endowed with an initial capital stock $k_{j}(0)>0$ and a fixed stock of labor, normalized to one. The budget constraint of the representative household in country $j$ is

$$
p_{j}(t)\left[\dot{k}_{j}(t)+c_{j}(t)\right]=p_{j}(t) Y_{j}(t)=r_{j}(t) k_{j}(t)+w_{j}(t)
$$

We assume that varieties are differentiated by origin, and each country produces a measure $\mu_{j}$ of these differentiated varieties, so that

$$
\sum_{j=1}^{J} \mu_{j}=N
$$

where $N$ is the total number of varieties. In the baseline model we assume that the number of varieties is exogenously given by $\mu_{j}=\kappa \theta_{j}$, where $\kappa>0$. It implies that more productive countries produce a larger number of varieties. Online Appendix C provides an exact 
microfoundation of this production function of varieties.

The final good is produced according to the constant returns to scale production function

$$
Y_{j}(t)=\exp \left(\int_{0}^{N} \frac{1}{N} \ln x_{j}(v, t) d v\right),
$$

where $x_{j}(v, t)$ denotes the amount of varieties used in final good production in country $j$. The production of varieties requires a bundle of intermediates, indexed by $z \in[0,1]$,

$$
x_{j}(v, t)=\exp \left[\int_{0}^{1} \beta(z) \ln a_{j}(z, v, t) d z\right],
$$

where $a_{j}(z, v, t)$ denotes the amount of intermediate $z$ used at time $t$ to produce variety $v$ in country $j . \beta(z)$ reflects the relative importance of intermediate $z$ in the production of variety $v$. We assume, for simplicity, that $\beta(z)=1$. In Section 4.2 we study the effects of computerization and make comparative statics on $\beta(z)$.

Intermediates are produced using labor $l$ and capital $k$ in different proportions,

$$
a_{j}(z, t)=\theta_{j}\left(\frac{k_{j}(z, t)}{z}\right)^{z}\left(\frac{l_{j}(z, t)}{1-z}\right)^{1-z}, \quad z \in[0,1]
$$

where $a_{j}(z, t)$ denotes total production of intermediate $z$ at time $t$ in country $j$ and $\theta_{j}$ denotes the productivity in country $j$.

\subsection{Equilibrium Without Unbundling}

This subsection analyzes the competitive equilibrium without unbundling. That is, when varieties are traded but intermediates cannot be traded between countries. We characterize the steady-state competitive equilibrium and show that the world income share of a country is determined by the share of varieties it produces.

Definition 1 A competitive equilibrium without unbundling is defined by a sequence of prices $\left\{w_{j}(t), r_{j}(t), p_{j}(t), p_{j}(v, t), p_{j}(z, t)\right\}$ and allocations $\left\{l_{j}(z, t), k_{j}(z, t), c_{j}(t), a_{j}(z, v, t), a_{j}(z, t)\right.$, $\left.x_{j}(v, t)\right\}$ for $t=0, \ldots, \infty$ and $j=1, \ldots, J$, such that for each country: (i) the representative agent maximizes utility subject to the budget constraint, (ii) final good producers maximize

profits given prices, (iii) variety producers maximize profits given prices, (iv) intermediate producers maximize profits given prices, (v) labor and capital market clear and (vi) trade in varieties is balanced for each country. 
The consumer utility maximization problem (1) subject to the budget constraint (2) yields

$$
\begin{array}{r}
\frac{\dot{c}_{j}(t)}{c_{j}(t)}=\frac{r_{j}(t)}{p_{j}(t)}-\rho, \\
\lim _{t \rightarrow \infty} e^{-\rho t} c_{j}(t)^{-1}\left(\frac{r_{j}(t)}{p_{j}(t)} k_{j}(t)\right)=0 .
\end{array}
$$

Equation (7) is the Euler Equation from a standard Ramsey model, with the price $p_{j}$ made explicit, as it may differ across countries. Equation (8) is the transversality condition.

Omitting the time index $t$, the problem of the final good producer in country $j$ is to

$$
\max _{x_{j}(v)} p_{j} Y_{j}-\int_{0}^{N} p_{j}(v) x_{j}(v) d v,
$$

where $Y_{j}$ is given by (4). It follows that

$$
\frac{p_{j} Y_{j}}{N}=p_{j}(v) x_{j}(v)
$$

Thus, as varieties are traded, the total demand of variety $v$ is

$$
x(v)=\sum_{i=1}^{J} x_{j}(v)=\frac{1}{N} \frac{\sum_{i=1}^{J} p_{j} Y_{j}}{p_{j}(v)} .
$$

The problem of variety- $v$ producer in country $j$ is

$$
\max _{a_{j}(z, v)} p_{j}(v) x_{j}(v)-\int_{0}^{1} p_{j}(z) a_{j}(z, v),
$$

which implies that the demand of intermediate $z$ to produce variety $v$ is pinned down by

$$
p_{j}(z) a_{j}(z, v)=p_{j}(v) x_{j}(v)=x_{j}(v) \exp \left(\int_{0}^{1} \ln p_{j}(z) d z\right) .
$$

Since there is not trade in intermediates, the aggregate demand of intermediate $z$ in country $j$ comes only from the production of domestic varieties,

$$
a_{j}(z)=\mu_{j} a_{j}(z, v)
$$

where $\mu_{j}$ is the number of varieties produced in country $j$.

The problem of the producer of intermediate $z$ in country $j$ is

$$
\max _{l_{j}(z), k_{j}(z)} p_{j}(z) \theta_{j}\left(l_{j}(z)\right)^{1-z} k_{j}(z)^{z}-w_{j} l_{j}(z)-r_{j} k_{j}(z),
$$


which implies the following labor and capital demands

$$
\begin{aligned}
(1-z) p_{j}(z) a_{j}(z) & =w_{j} l_{j}(z) \\
z p_{j}(z) a_{j}(z) & =r_{j} k_{j}(z)
\end{aligned}
$$

Aggregating labor demand (10) across intermediates and noting that the labor supply is normalized to one, we obtain the labor market clearing condition

$$
1=\int_{0}^{1} l_{j}(z)=\frac{1}{w_{j}} \int_{0}^{1}(1-z) p_{j}(z) a_{j}(z) d z=\frac{1}{2} \mu_{j} \frac{\sum_{i} p_{i} Y_{i}}{N} \frac{1}{w_{j}} .
$$

Likewise, using (11), the capital market clearing condition is given by

$$
K_{j}=\frac{1}{r_{j}} \int_{0}^{1} z p_{j}(z) a_{j}(z) d z=\frac{1}{2} \mu_{j} \frac{\sum_{i} p_{i} Y_{i}}{N} \frac{1}{r_{j}} .
$$

To derive the trade balance equation, recall that without unbundling, only varieties are traded. Thus, the value of exported varieties $\mu_{j} p_{j}^{x}(v) x(v$, exported) (all varieties produced by one country are symmetric) has to be equal to the value of imported varieties,

$$
\underbrace{\frac{\mu_{j}}{N}\left(\sum_{i=1}^{J} p_{i} Y_{i}-p_{j} Y_{j}\right)}_{\text {Exports of Varieties }}=\underbrace{\frac{N-\mu_{j}}{N} p_{j} Y_{j}}_{\text {Imports of Varieties }} .
$$

All final goods are produced using the same varieties by competitive producers in all countries, thus, the prices of final goods are the same across countries $p_{i}=p_{j}$. Rewriting (12), we obtain

$$
\frac{\mu_{j}}{\sum_{i=1}^{J} \mu_{i}}=\frac{p_{j} Y_{j}}{\sum_{i=1}^{J} p_{i} Y_{i}}=\frac{Y_{j}}{\sum_{i=1}^{J} Y_{i}} .
$$

From the factor market clearing conditions, we can write the labor and capital income in country $j$ as

$$
\begin{aligned}
w_{j} & =\frac{1}{2} \kappa \theta_{j} \frac{\sum_{i} p_{i} Y_{i}}{N}, \\
r_{j} k_{j} & =\frac{1}{2} \kappa \theta_{j} \frac{\sum_{i} p_{i} Y_{i}}{N} .
\end{aligned}
$$

Using the trade balance equation (13) and the fact that the number of varieties produced in country $j$ is $\mu_{j}=\kappa \theta_{j}$, we can express the world income share of country $j$ as a function of the exogenous levels of productivity ${ }^{9}$

\footnotetext{
${ }^{9}$ Note that in Eaton and Kortum (2002), the number of varieties is also proportional to the productivity of the country. In their framework, the income share is also proportional to a re-scaled productivity measure in
} 


$$
s_{j} \equiv \frac{Y_{j}}{\sum_{i=1}^{J} Y_{i}}=\frac{\theta_{j}}{\sum_{i=1}^{J} \theta_{i}} .
$$

This equation means that the relative income of country $j$ is the relative productivity of the country.

Steady-state solution In the steady-state there is no growth, $\dot{k}=\dot{c}=0$. The Euler condition implies that the interest rate is equalized across countries (i.e., $r_{j}=\rho$ ). The consumption level is determined by the budget constraint, $c_{j}=p_{j} Y_{j}=w_{j}+\rho k_{j}$. Finally, note that the country ranking in income shares coincides with the welfare ranking in steady-state.

\subsection{Equilibrium With Unbundling}

This subsection characterizes the equilibrium with unbundling. In this case, both varieties and intermediates can be costlessly traded. This implies that countries no longer need to produce all intermediates required to produce varieties. Rather, they can specialize in a subset of these intermediates and import the rest. We show that the world income share depends on the mass of intermediates in which the country specializes.

Definition 2 A competitive equilibrium with unbundling is defined by a sequence of prices $\left\{w_{j}(t), r_{j}(t), p_{j}(t), p_{j}(v, t), p_{j}(z, t)\right\}$ and allocations $\left\{l_{j}(z, t), k_{j}(z, t), c_{j}(t), a_{j}(z, v, t), a_{j}(z, t)\right.$, $\left.x_{j}(v, t)\right\}$ for $t=0, \ldots, \infty, j=1, \ldots, J$, such that for each country: (i) the representative agent maximizes utility subject to the budget constraint, (ii) final good producers maximize profits given prices, (iii) variety producers maximize profits given prices, (iv) intermediate producers maximize profits given prices, (v) labor and capital market clear and (vi) trade in varieties and intermediates is balanced for each country.

To derive the equilibrium, we repeat the same steps as in Section 2.2. The demand of varieties is given by (9), as in the previous section. The key difference is that since intermediates are now costlessly traded, the producer of variety $v$ purchases intermediates from the cheapest location. Thus, the price of variety $v$ is given by

$$
\ln p_{j}(v)=\int_{0}^{1} \ln \left(\min _{j \in\{1, \ldots, J\}}\left\{p_{j}(z)\right\}\right) d z .
$$

This implies that the aggregate demand of intermediate $z$ in country $j$, rather than coming from the domestic demand as in the equilibrium without unbundling, comes now from the entire world, provided that country $j$ produces $z$ at the cheapest world price. ${ }^{10}$ Thus, the

the zero-gravity case.

${ }^{10}$ We are implicitly assuming that each intermediate is done only by one country, which is indeed true almost everywhere in equilibrium. 
mass of intermediates that each country produces is endogenously determined. Denoting by $Z_{j}$ the mass of intermediates that country $j$ produces in the unbundling equilibrium, we have that

$$
a_{j}(z)=\sum_{i=1}^{J} \mu_{i} a_{j}(z, v)=N a_{j}(z, v), \quad \text { if } z \in Z_{j},
$$

and zero otherwise. Substituting the expression for $a_{j}(z, v)$ into equation (9) and using that $p_{j}(v) x(v)=p_{j}(z) a_{j}(z, v)$, we find that the total value of intermediate $z$ produced in country $j$ is

$$
p_{j}(z) a_{j}(z)=\sum_{i} p_{i} Y_{i}
$$

The expressions for the demand of labor and capital are as in the equilibrium without unbundling, (10) and (11), adjusting for the fact that each country only produces a subset $Z_{j}$ of the intermediates,

$$
\begin{aligned}
1 & =\int_{z \in Z_{j}}(1-z) d z \frac{1}{w_{j}} \sum_{i=1}^{J} p_{i} Y_{i}, \\
K_{j} & =\int_{z \in Z_{j}} z d z \frac{1}{r_{j}} \sum_{i=1}^{J} p_{i} Y_{i} .
\end{aligned}
$$

The trade balance changes with unbundling because now intermediates are also traded. Trade balance implies that the value of exported varieties plus the value of exported intermediates has to be equal to the value of imports of any country, ${ }^{11}$

$$
\underbrace{\frac{\mu_{j}}{N}\left(\sum_{i=1}^{J} p_{i} Y_{i}-p_{j} Y_{j}\right)}_{\text {Exports of Varieties }}+\underbrace{Z_{j} \frac{N-\mu_{j}}{N} \sum_{i=1}^{J} p_{i} Y_{i}}_{\text {Exports of Intermediates }}=\underbrace{\frac{N-\mu_{j}}{N} p_{j} Y_{j}}_{\text {Imports of Varieties }}+\underbrace{\left(1-Z_{j}\right) \frac{\mu_{j}}{N} \sum_{i=1}^{J} p_{i} Y_{i}}_{\text {Imp. of Intermediates }}
$$

After rearranging terms, the above expression simplifies to

$$
s_{j}=\frac{p_{j} Y_{j}}{\sum_{i} p_{i} Y_{i}}=Z_{j}
$$

This equation means that with unbundling the world income share of country $j$ is only determined by the mass of intermediates that the country produces. Note that a country is a net exporter of intermediates when it specializes in a larger share of intermediates than the fraction of varieties it produces (i.e., $Z_{j}>\frac{\mu_{j}}{N}$ ). It implies that unless $Z_{j}=\frac{\mu_{j}}{N}$, there will be

\footnotetext{
${ }^{11}$ To derive the value of exported intermediates, note that, for a given intermediate $z$, each variety producer demands $\frac{1}{N} \sum_{i} p_{i} Y_{i}$. Given that country $j$ produces $\mu_{j}$ varieties, the value of a given intermediate $z$ that goes into exporting is $\frac{N-\mu_{j}}{N} \sum_{i} p_{i} Y_{i}$. Finally, since country $j$ produces the range $Z_{j}$ of intermediates, the total value of exported intermediates is $Z_{j} \frac{N-\mu}{N} \sum_{i} p_{i} Y_{i}$. The computation for the value of imports can be done in an analogous way.
} 
an imbalance in intermediates trade and the income share will change with unbundling.

The productivity level of a country $\theta_{j}$ affects the income share (17) only through the endogenous selection of intermediates $Z_{j}$. The reason is that we assume that all value added comes from the production of intermediates. We show in Online Appendix D that if some intermediates cannot be traded (which is equivalent to introduce capital and labor as direct inputs in the production of intermediates 5), then the productivity of a country also enters directly in the income share equation (17). ${ }^{12}$ We choose to focus on comparing the two extremes cases (intermediate are either traded or non-traded), instead of making comparative statics in the share of traded intermediates, to better understand the distinctive effects of unbundling. However, this alternative model could be used to perform a quantitative analysis of the effects of unbundling, which we leave for future research. ${ }^{13}$

\subsubsection{Steady-state solution}

The final step is to derive the equilibrium share of intermediates that each country produces, $Z_{j}$. We proceed by focusing on the steady-state equilibrium.

From the Euler equation, (7), the rental rates are equalized across countries in the steadystate, $r_{j}=\rho$. Therefore, the cost of producing intermediate $z$ in country $j$ is

$$
c_{j}(z)=\theta_{j}^{-1} w_{j}^{1-z} \rho^{z}
$$

This implies that the most capital-intensive intermediate $(z=1)$ is produced by the most productive country, country 1 , because $c_{1}(1)=\theta_{1}^{-1} \rho=\min _{j}\left\{c_{j}\right\}$.

Let $p(z)=\min _{j}\left\{c_{j}\right\}$. Consider an intermediate $\tilde{z}<1$ with price $p(\tilde{z})$. Perfect competition implies that

$$
p(\tilde{z})-c_{j}(\tilde{z}) \leq 0
$$

Then, if two countries produce the same intermediate it has to be the case that

$$
c_{j}(\tilde{z})=c_{i}(\tilde{z}) \quad \Longrightarrow \quad \theta_{j}^{-1} w_{j}^{1-\tilde{z}}=\theta_{i}^{-1} w_{i}^{1-\tilde{z}}
$$

\footnotetext{
${ }^{12}$ In particular, Online Appendix D shows that if only a fraction $\alpha$ of each intermediate $z$ can be traded at no cost, and the reminder fraction $1-\alpha$ has to be produced domestically, the income share of country $j$ is given by $s_{j}=(1-\alpha) \frac{\theta_{j}}{\sum_{j} \theta_{j}}+\alpha_{j} Z_{j}$, where $Z_{j}$ is the mass of traded intermediates produced in country $j$. Note that when $\alpha=0$ this expression becomes the solution of the equilibrium without unbundling and when $\alpha=1$ the equilibrium with unbundling.

${ }^{13}$ From a theoretical standpoint, our unbundling equilibrium has the following additional property. The income share (17) coincides with what we would obtain in a standard Heckscher-Ohlin model in which the final good is directly produced using intermediates, and only intermediates are traded. The trade balance would be $Z_{j}\left(\sum_{i} p_{i} Y_{i}-Y_{j}\right)=\left(1-Z_{j}\right) p_{j} Y_{j}$. Thus, our results for the unbundling equilibrium can be interpreted as solving this equivalent dynamic Heckscher-Ohlin model. It is in this sense that we claim to contribute to this literature in the introduction.
} 
which implies that

$$
\frac{w_{i}}{w_{j}}=\left(\frac{\theta_{i}}{\theta_{j}}\right)^{\frac{1}{1-\tilde{z}}} .
$$

Suppose that $j>i$, so that $\theta_{j}<\theta_{i}$. As $\frac{1}{1-z}$ is an increasing function of $z$, this implies that country $j$ will not produce any intermediate with $z>\tilde{z}$. Thus, we have a sequence of thresholds $z_{j}$ that determines the pattern of specialization in intermediates,

$$
\frac{w_{j}}{w_{j+1}}=\left(\frac{\theta_{j}}{\theta_{j+1}}\right)^{\frac{1}{1-z_{j}}} \text { for all } j \text {. }
$$

We have derived two equilibrium conditions relating the equilibrium wages and the equilibrium thresholds: labor market clearing (equation 16) and the definition of the threshold intermediate (equation 18). Using the ratio of both equations, we obtain the following endogenous selection of intermediates.

Remark The endogenous selection of intermediates is given by the second order difference equation,

$$
\begin{aligned}
\left(\frac{\theta_{j}}{\theta_{j+1}}\right)^{\frac{1}{1-z_{j}}} & =\frac{\Delta_{j}}{\Delta_{j+1}} \\
\text { where } \Delta_{j} & =\int_{z_{j}}^{z_{j-1}}(1-z) d z
\end{aligned}
$$

with terminal conditions $z_{0}=1$ and $z_{J}=0 .{ }^{14}$

An implication of this endogenous selection of intermediates is that countries with relatively high-productivity have comparative advantage in high $z$ intermediates and export capital-intensive intermediates. This is in line with the findings in Schott (2004), who documents that richer countries specialize in capital-intensive goods. Baxter and Kouparitsas (2003), Hanson (2012) and Schott (2003a,b) also find similar results. ${ }^{15}$ We also provide additional evidence consistent with this pattern of specialization. Consider the following equation

$$
X_{i c t}=\alpha+\beta \cdot \mathrm{TFP}_{c} \cdot \text { Capital Intensity } i t+\delta_{i t}+\delta_{c t}+\varepsilon_{i c t},
$$

where $X_{i c t}$ is the $\log$ of total exports of intermediates $i$ of country $c$ at time $t, \mathrm{TFP}_{c}$ is total factor productivity of country $c, \delta_{i t}, \delta_{c t}$ are intermediate-year and country-year fixed effects,

\footnotetext{
${ }^{14}$ Note that the left-hand side is continuous and increasing in $z_{j}$ and the right-hand side is continuous and decreasing in $z_{j}$. Therefore, the solution is unique.

${ }^{15}$ Bernard et al. (2006) find that U.S. manufacturing reallocates away from labor-intensive towards capitalintensive plants within industries, as industry exposure to imports from low-wage countries rises. At a more aggregate level, Davis and Weinstein (2001) and Romalis (2004) also provide evidence consistent with this pattern of specialization.
} 
respectively. Our data is for the period 1994-2008. The prediction of the model is $\beta>0$. That is, relatively high-productivity countries have comparative advantage in capital-intensive industries. ${ }^{16}$ Columns (1) to (4) in Table 1 report the coefficient $\beta$ of the regression for different sets of fixed effects. Consistent with the model, the coefficient is positive and significant at a $1 \%$ level in all specifications. Standard errors are clustered at country level. Quantitatively, our most conservative estimate, the interaction term in column (1), implies that increasing TFP from the 25 th percentile to the $75 \mathrm{th}$, would increase exports in the 75 th percentile capital-intensive sectors a $18 \%$. For the 25 th percentile capital-intensive intermediates, the increase would be a $13 \% .{ }^{17}$ Thus, if TFP were to move from the 25 th to the 75 th percentile, the increase in intermediate exports in the 75 th percentile of capital-intensity would be a $40 \%$ higher than the rise in those of the 25 th percentile.

\section{Main Results}

This section compares the equilibrium with and without unbundling and derives the main results of the paper. We first consider a world of ex-ante identical countries and show that unbundling of production generates symmetry breaking. We next study a world consisting of heterogenous countries and show that unbundling raises top-bottom inequality and that middle-productivity countries experience the largest decline in income share. All omitted proofs are in the Online Appendix.

\subsection{Symmetry Breaking of ex-ante Identical Countries}

To build intuition, we start analyzing the two-country case. Then, we characterize the equilibrium for a world with an arbitrary number of countries.

\subsubsection{The two-country case}

Suppose that the world consists of two identical countries, $J=\{1,2\}$ with $\theta_{1}=\theta_{2}=\theta$. In the equilibrium without unbundling, each country has half of the world income share,

$$
\frac{s_{1}^{\text {without }}}{s_{2}^{\text {without }}}=\frac{\theta_{1}}{\theta_{2}}=1 .
$$

\footnotetext{
${ }^{16}$ We classify goods as intermediates using the classification in Feenstra and Jensen (2012). Our data stops in 1994 because prior to this year we do not have the same level of disaggregation. Note that we are making the standard assumption that the ranking of capital-intensive industries is stable across countries, as our capital-intensity data comes from the U.S. only. All data sources and definitions can be found in Table 1.

${ }^{17}$ The 25th percentile of TFP corresponds to Cameroon, with a measure of .274 . The 75 th percentile corresponds to Israel, with a measure of .817. Note that Hall and Jones (1999) report TFP relative to the U.S. TFP. For the sample period, the 25th percentile of capital-intensity corresponds to NAICS 313312 (Textile and Fabric Finishing) with a measure of .271. The 75th percentile of capital-intensity corresponds to NAICS 327125 (Nonclay Refractory Manufacturing) with a measure of .373.
} 
In the equilibrium with unbundling, the endogenous selection of intermediates changes the world income shares. The difference equation (19) determining the specialization threshold becomes

$$
1=\frac{\frac{1}{2}-\left(z-\frac{z^{2}}{2}\right)}{\left(z-\frac{z^{2}}{2}\right)},
$$

where we have used the terminal conditions $z_{0}=1, z_{2}=0$ and $\theta_{1}=\theta_{2}=\theta$. There exists a unique solution to this equation given by $z^{*}=1-\sqrt{1 / 2}$. That is, country 1 specializes in the production of intermediates $z \in\left(z^{*}, 1\right]$ and country 2 produces the rest of intermediates, $z \in\left[0, z^{*}\right)$. Thus, in the unbundling equilibrium, the relative income share of country 1 becomes

$$
\frac{s_{1}^{\text {with }}}{s_{2}^{\text {with }}}=\frac{Z_{1}}{Z_{2}}=\frac{1-z^{*}}{z^{*}}=\frac{1}{\sqrt{2}-1}>1 .
$$

We have established the following result.

Proposition 1 Consider a world with two ex-ante identical countries. Without unbundling of production, the income share of the two countries is the same. With unbundling of production, the two countries end up with strictly different world income shares.

Equation (21) shows that the country that specializes in more capital-intensive intermediates becomes richer in the steady-state with unbundling, even though the two countries have the same productivity. The intuition is that the country that specializes in more capital-intensive intermediates accumulates more capital, which gives this country additional comparative advantage in producing capital-intensive intermediates. There exists also a symmetric equilibrium, but it is unstable. Suppose we start with a symmetric equilibrium in which both countries produce all intermediates in the same amount. Consider a small positive perturbation to the productivity of country 1 . Country 1 gains comparative advantage on the production of capital-intensive intermediates. Once country 1 starts producing more capital-intensive intermediates, it accumulates more capital, which reinforces the pattern of comparative advantage. Thus, even if the initial perturbation vanishes, country 1 retains the comparative advantage in capital-intensive intermediates. Online Appendix B contains a formal description of this perturbation argument. It also shows that the threshold equilibrium we characterize is unique once we allow for arbitrary small perturbations in productivity. ${ }^{18}$

Another way to understand this result is that unbundling of production changes the production function of countries. Without unbundling, all countries have the same aggregate production function because they have the same productivity and they produce the same intermediates. However, with unbundling, each country only produces a set of intermediates. Since these intermediates differ on capital-intensity, the capital share of the aggregate

\footnotetext{
${ }^{18}$ In Online Appendix D.2, we show that exactly the same thresholds solve the assignment when only a fraction $\alpha$ of intermediates are traded. Thus, symmetry breaking occurs as long as $\alpha>0$.
} 
production function is larger in country 1 . This causes that in the steady-state country 1 accumulates more capital. Therefore, both countries have the same capital without unbundling, but country 1 accumulates more capital than country 2 in the equilibrium with unbundling.

Finally, we decompose the change in world income between changes in the relative labor and capital income. If we compare labor and capital income between countries in the equilibrium with and without unbundling, we have that

$$
\begin{aligned}
&\left(\frac{w_{2}}{w_{1}}\right)^{\text {with }}-\left(\frac{w_{2}}{w_{1}}\right)^{\text {without }}=\left(\frac{\theta_{2}}{\theta_{1}}\right)^{\frac{1}{1-z^{*}}}-\frac{\theta_{2}}{\theta_{1}}=0, \\
&\left(\frac{\rho k_{2}}{\rho k_{1}}\right)^{\text {with }}-\left(\frac{\rho k_{2}}{\rho k_{1}}\right)^{\text {without }}=\frac{z^{* 2}}{1-z^{* 2}}-\frac{\theta_{2}}{\theta_{1}}<0,
\end{aligned}
$$

where we have used the definition of $z^{*}$ and that $\theta_{1}=\theta_{2}$. In relative terms, the labor income remains unchanged between countries with unbundling. Country 2 relatively loses in capital income. The reason is that it specializes in relatively less capital-intensive intermediates, thereby accumulating less capital in the steady-state.

World Output and Steady-State Welfare In the Online Appendix G.1 we derive the total output produced in the world under the two trade regimes. By using that the final good is the numéraire, we show that the world output is the same with and without unbundling and equal to

$$
Y^{\mathrm{World}}=\frac{4 \theta^{2}}{\rho} .
$$

The intuition for this result is that since the two countries have the same productivity, changing the allocation of intermediates does not change the aggregate production. Given that the income share strictly changes with unbundling, it implies that the income in the ex-post rich country increases, whereas the income in the ex-post poor country falls. It follows that welfare in the steady-state unbundling equilibrium is higher in the ex-post rich country and lower in the ex-post poor country. ${ }^{19}$

\subsubsection{A world with a large number of ex-ante identical countries}

The symmetry breaking result extends to a world with a large number of countries that are identical in terms of their productivity, $\theta(j)=\theta$. In this case, equation (19) reduces to

$$
\Delta_{j}=\Delta_{j+1} \quad \text { for all } \quad j=1, \ldots, J-1 .
$$

\footnotetext{
${ }^{19}$ In order to do a complete welfare assessment, we would need to compute the transition between the two steady-states. Thus, it could be that for very high discount factors, countries that reduce their steady-state consumption with unbundling are better off. We note that for sufficiently patient agents the steady-state income levels would be the only term pinning down the welfare gains of unbundling.
} 
Using the boundary conditions $z_{0}=1$ and $z_{J}=0$, we obtain the following result.

Proposition 2 Consider a world with $J$ ex-ante identical countries in terms of their productivity level $\theta$. Without unbundling of production, the world income share of each country is identical and equal to $1 / J$. With unbundling of production, symmetry breaking occurs. Country $j$ specializes in the set of intermediates $\left(z_{j}, z_{j-1}\right]$ with

$$
z_{j}=1-\sqrt{\frac{j}{J}}
$$

and its world income share becomes $\sqrt{\frac{j}{J}}-\sqrt{\frac{j-1}{J}}$.

Note that the threshold in equation (22) is a decreasing and convex function of $j$. Thus, while all countries have an equal share of the world income in the equilibrium without unbundling, inequality emerges among ex-ante identical countries in the equilibrium with unbundling. The trade balance equation (17) implies that the world income share of country $j$ is

$$
s_{j}=Z_{j},
$$

where $Z_{j}$ is endogenously determined from the specialization in intermediates and differs across countries.

$$
Z_{j}=z_{j-1}-z_{j}=\sqrt{\frac{j}{J}}-\sqrt{\frac{j-1}{J}} .
$$

This term is decreasing and convex, which means that countries that specialize in capitalintensive intermediates have a higher income share. ${ }^{20}$

Lorenz Curve of World Output We can characterize the Lorenz curve of the world income distribution using the expression of the world income shares,

$$
L(j)=\sum_{i=J}^{j} s_{i}=1-\sqrt{\frac{j-1}{J}}, \quad j=1, \ldots, J,
$$

which is an increasing and convex function. Note that the ordering of countries for the Lorenz curve is descending in the country index $j$. It starts with $j=J$, with $L(J)=1-\sqrt{1-1 / J}$, and it ends at $j=1$, with $L(1)=1$. These heterogeneous income shares are in contrast with the complete equality benchmark in the equilibrium without unbundling, which has a linear Lorenz curve, $L(j)=j / J$.

As in Matsuyama (2013), the model does not have a prediction as to which specific country will occupy rank- $j$ in the world economy, but it shows that endogenous inequality will emerge.

\footnotetext{
${ }^{20}$ The first derivative is proportional to $j^{-1 / 2}-(j-1)^{-1 / 2}$, which is negative for $j>1$. The second derivative is proportional to $-j^{-3 / 2}+(j-1)^{-3 / 2}$, which is positive for $j>1$.
} 
Notice that a symmetric equilibrium (all countries produce equal shares of all intermediates and, thus, have the same income) would also potentially be possible in this case. However, the intuition for the two-country case carries over to this general case. The symmetric equilibrium is not stable to small perturbations to productivity. As one country starts producing more capital-intensive intermediates, it accumulates more capital, which reinforces the initial comparative advantage in capital-intensive intermediates. Online Appendix B introduces formally the equilibrium refinement concept of arbitrarily small perturbations to productivity. It shows that under this refinement, our threshold equilibrium is unique up to permutations in the country ordering. ${ }^{21}$

World Output and Steady-State Welfare Normalizing the price of the final good to one, we show in Online Appendix G.1 that the total output produced in the world in the steady-state equilibria with and without unbundling coincide. The world output is

$$
Y^{\mathrm{World}}=\frac{2 J \theta^{2}}{\rho} .
$$

The intuition for the result is that, as all countries are technologically identical, the aggregate world output does not change. Therefore, the differences in income shares $s_{j}$ generated with unbundling of production inform us on the changes in level of steady-state consumption and, thus, on steady-state welfare. It implies that the steady-state welfare rises in the countries in which the income share increases, while it falls in the rest of countries.

Within-country Inequality We also analyze the emergence of within-country inequality. The change in the Theil index in country $j$ is ${ }^{22}$

$$
\Delta T_{j}=\left(1-\frac{1}{2 J Z_{j}}\right) \ln \left(2 J Z_{j}-1\right)-\ln \left(J Z_{j}\right) .
$$

The change in inequality has a U-shape in the country index $j$, with its minimum being equal to zero at

$$
j=\frac{(1+J)^{2}}{4 J} .
$$

\footnotetext{
${ }^{21}$ Note that the symmetry breaking result holds if we had assumed that varieties also differ on capitalintensity requirements, $\ln Y_{j}=\int_{0}^{1} \beta_{j}(z) \ln a_{j}(z, v) d z$ provided that each country produced varieties with the same distribution of capital-intensity requirements. The reason is that we assume that varieties are differentiated by origin (Armington assumption). In this case, we would also have that ex-ante identical countries have the same world output share in the equilibrium without unbundling. Unbundling of production would generate symmetry breaking for the same logic as in the main text.

${ }^{22}$ Suppose we have $N$ measures of income $x_{i}, i=1, \ldots, N$, with arithmetic mean $\bar{x}$. The Theil index is

$$
T=\frac{1}{N} \sum_{i=1}^{N} \frac{x_{i}}{\bar{x}} \ln \left(\frac{x_{i}}{\bar{x}}\right) .
$$
}


Thus, unbundling generically increases within-country inequality in all countries. The Ushape of $\Delta T_{j}$ implies that the rise in within-country inequality is the highest at the extremes of the support of the country indices. ${ }^{23}$ The recurrence equation (19) implies that the wage bill is equalized across countries. Thus, all changes in inequality come through differences in capital accumulation. Since the steady-state level of capital is monotonically decreasing in the country index, this provides an intuition for the U-shape result in the change in withincountry inequality. The difference in income obtained from capital and labor is maximized for the countries that accumulate the most and the least capital.

\subsection{Heterogenous Countries}

In this section we study how the world income distribution changes when countries are heterogenous and differ in their productivity level. We first consider a world that consists of two countries and show that inequality increases with unbundling. Then, we show that this result extends to a large number of countries and provide the additional result that middleproductivity countries are the most likely to lose with unbundling of production.

\subsubsection{The two-country case}

Consider a world that consists of two countries with different productivity levels. Let us assume that $\theta_{1}>\theta_{2}$ and, without loss of generality, $\theta_{1}+\theta_{2}=1$. The threshold $z^{*}$ that divides the intermediates produced by each country is given by

$$
A(\theta, z)=\left(\frac{\theta_{1}}{\theta_{2}}\right)^{\frac{1}{1-z}}=\frac{(1-z)^{2}}{z(2-z)}=B(z) .
$$

The solution to this equation $z^{*}$ is unique. Moreover, $z^{*}$ is continuous and monotonically decreasing with $\theta_{1} / \theta_{2}$. The reason is that the larger is the productivity difference between the two countries, the larger is the share of intermediates that country 1 produces. Note that this implies that inequality in the unbundling equilibrium is greater with heterogeneous countries than with countries with the same productivity.

Proposition 3 Inequality between countries increases with unbundling of production.

\footnotetext{
${ }^{23}$ For the particular case of $J=2$, the Theil index for country $j$ becomes $\Delta T_{j}=\left(1-\frac{1}{4 Z_{j}}\right) \ln \left(4 Z_{j}-1\right)-$ $\ln \left(2 Z_{j}\right)$, which is .049 for country 1 and .275 for country 2 . Note that if the production function of varieties were a bundle of intermediates of $z$ aggregated with weight $\beta(z)$, such that the aggregate demand of capital and labor does not satisfy $\int_{0}^{1} z \beta(z) d z=\int_{0}^{1}(1-z) \beta(z) d z$, inequality could decrease for some countries. However, the U-shape result would still hold, and inequality would be maximized for the countries with the highest and the lowest productivity.
} 
We can write the change in the relative income of country 2 between the two equilibria as

$$
s_{2}^{\text {with }}-s_{2}^{\text {without }}=z^{*}-\theta_{2} \text {. }
$$

The difference in relative income share is negative, which means that unbundling of production leads to more inequality between the two countries. The reason is that the rich country specializes in more capital-intensive intermediates, thereby accumulating more capital and increasing the income gap between the two countries.

To better understand this result, we decompose the change in world income between changes in the relative labor and capital income,

$$
\begin{aligned}
\left(\frac{w_{2}}{w_{1}}\right)^{\text {with }}-\left(\frac{w_{2}}{w_{1}}\right)^{\text {without }} & =\left(\frac{\theta_{2}}{\theta_{1}}\right)^{\frac{1}{1-z^{*}}}-\frac{\theta_{2}}{\theta_{1}}<0, \\
\left(\frac{\rho k_{2}}{\rho k_{1}}\right)^{\text {with }}-\left(\frac{\rho k_{2}}{\rho k_{1}}\right)^{\text {without }} & =\frac{z^{* 2}}{1-z^{* 2}}-\frac{\theta_{2}}{\theta_{1}}<0 .
\end{aligned}
$$

Country 2 relatively loses in both sources of income with unbundling. For relative wages, note that unless the two countries have the same productivity (which is the case we analyzed in the previous section), the new relative wage will be lower in country 2 (because $z^{*}>0$ ). For capital income, country 1 specializes in more capital-intensive intermediates, thereby accumulating more capital in the steady-state. Therefore, unbundling of production exacerbates the inequality between the two countries both in capital and labor income.

World Output and Steady-State Welfare We can also compute the steady state levels of world output for the case of two heterogenous countries (see Online Appendix G.2 for the detailed derivations). We find that the expressions for world output in both steady-states are

$$
\begin{aligned}
Y^{\text {World, without }} & =\frac{2}{\rho} \theta_{1}^{\theta_{1}} \theta_{2}^{\theta 2}, \\
Y^{\text {World, with }} & =\frac{1}{\rho z^{*}\left(2-z^{*}\right)} \theta_{1}^{1-z^{*}} \theta_{2}^{1+z^{*}} .
\end{aligned}
$$

It is straighforward to see that $Y^{\text {World, with }}>Y^{\text {World, without }}$. Thus, world output increases with unbundling. The reason is that in the unbundling equilibrium the more productive country produces a larger set of intermediates, which is a more efficient use of resources and it results in a higher level of world output. Welfare in the more productive country increases with unbundling. Its income share of world output increases and world output also increases. For the less productive country there are two opposite effects. On the one hand, the world output increases with unbundling. On the other hand, its income share declines. In Online Appendix G.2 we show that the latter effect always dominates and country 2 has a lower level 
of output and welfare in the steady state with unbundling.

\subsubsection{A world with a large number of countries}

Equation (19) characterizes the assignment of countries to the production of intermediates. Unfortunately, equation (19) is not analytically solvable. To simplify the problem, we take the same approach as in Matsuyama (2013). We approximate the solution to the case in which the number of countries is very large, $J \rightarrow \infty$. In this case, equation (19) converges to a second-order differential equation. Making parametric assumptions on the distribution of $\theta_{j}$ allows us to solve the assignment problem.

Define a new country index $\omega=j \varepsilon$ for $\varepsilon>0$ and $j=1,2, \ldots, J$. We proceed by taking the limit $\varepsilon \rightarrow 0$ and $J \rightarrow \infty$ such that $\lim _{\varepsilon \rightarrow 0, J \rightarrow \infty} \varepsilon J=\bar{\omega} \leq \infty$. Equation (19) becomes

$$
\left(\frac{\theta_{\omega+\varepsilon}}{\theta_{\omega}}\right)^{\frac{1}{1-z_{\omega}}}=\frac{\Delta_{\omega+\varepsilon}}{\Delta_{\omega}}
$$

Taking Taylor series expansions around $\varepsilon=0$ for the left-hand side of equation (23) we obtain

$$
\left(\frac{\theta_{\omega+\varepsilon}}{\theta_{\omega}}\right)^{\frac{1}{1-z_{\omega}}}=1+\frac{1}{1-z(\omega)} \frac{\theta^{\prime}(\omega)}{\theta(\omega)} \varepsilon+o(\varepsilon)^{2} .
$$

Note that we are assuming that, as countries become arbitrarily close $(\varepsilon \rightarrow 0)$, so do their productivities. In other words, we assume that $\theta(\omega)$ is a smooth function with a well defined derivative in its domain. For the right-hand side, we find that

$$
\frac{\Delta_{\omega+\varepsilon}}{\Delta_{\omega}}=1+\left(\frac{z^{\prime \prime}(\omega)}{z^{\prime}(\omega)}-\frac{z^{\prime}(\omega)}{1-z(\omega)}\right) \varepsilon+o(\varepsilon)^{2}
$$

Taking the limit as $J \rightarrow \infty$, so that all terms of order higher than $\varepsilon$ are negligible, we find that $z(j)$ has to satisfy the following second-order differential equation

$$
(1-z(\omega)) \frac{z^{\prime \prime}(\omega)}{z^{\prime}(\omega)}-z^{\prime}(\omega)=\frac{\theta^{\prime}(\omega)}{\theta(\omega)}
$$

with terminal conditions $z(0)=1$ and $z(\bar{\omega})=0$.

We know from the equilibrium assignment that more productive countries specialize in capital intensive (higher index $z$ ) intermediates, $z^{\prime}(\omega)<0$. Thus, $\theta^{\prime}(\omega) z^{\prime}(\omega)>0$. Rearranging (24), we find that $z(\omega)$ is convex, as $z^{\prime \prime}(\omega)=(1-z(\omega))^{-1}\left(\theta^{\prime}(\omega) z^{\prime}(\omega) / \theta(\omega)+z^{\prime 2}(\omega)\right)>0$.

Notation change. In what follows, we abuse notation and use $j$ to denote the continuous country index $\omega$.

The differential equation governing the assignment process (24) is a non-linear differential equation, which cannot be characterized in analytical form without making parametric 
assumptions on $\theta(j)$. To make further progress in the analysis, we specialize $\theta(j)$ to be a distribution that approximates well the data. Our theory suggests that $\theta_{j}$ can be obtained by looking at the distribution of TFP across countries or, alternatively, at the world income distribution without unbundling, equation (15), which is also proportional to $\theta_{j}$. Figure I.1 in Online Appendix reports the distribution of TFP and income per capita shares in $1988 .{ }^{24}$ We find that the exponential fit is remarkably good. The $R^{2}$ of TFP on the country ranking is .97 , and .99 for income shares. ${ }^{25}$ Thus, we proceed making the following assumption.

\section{Assumption 1 Countries' productivity $\theta$ is exponentially distributed,}

$$
\theta(j)=\lambda \exp (-\lambda j), \quad j \in[0, \infty)
$$

Note that the most productive country, $j=0$, has productivity level $\theta(0)=\lambda$ and productivity is decreasing in $j$. Given this particular functional form, the differential equation (24) becomes

$$
(1-z(j)) \frac{z^{\prime \prime}(j)}{z^{\prime}(j)}-z^{\prime}(j)=-\lambda,
$$

with terminal conditions $z(0)=1$ and $z(\infty)=0$. Making the change of variables

$$
v(1-z(j))=\frac{d(1-z(j))}{d j}=-z^{\prime}(j)
$$

equation (24) can be written as

$$
v(1-z)\left(\lambda+(1-z) v^{\prime}(1-z)+v(1-z)\right)=0
$$

where we have used that $-z^{\prime \prime}(j)=v(1-z) v^{\prime}(1-z)$. There are two solutions to this equation. The relevant solution is given by the terms inside the brackets (the other solution is to have $z(j)$ being constant, so that $v(1-z)=0)$. Integrating the terms inside brackets and applying the boundary conditions, we can characterize the inverse of the assignment function,

$$
j(z)=\frac{z+\ln z^{-1}-1}{\lambda},
$$

which is monotonically decreasing in $z$. It is possible to invert this function and obtain $z(j)$, although the expression involves a transcendental function,

$$
z(j)=-W(-\exp (-1-\lambda j))
$$

\footnotetext{
${ }^{24}$ The election of 1988 is given by our data source, Hall and Jones (1999), which report TFP data for this year. Note that it coincides with the change in trade regime documented in Figure 1.

${ }^{25}$ This fit is better than a Pareto, which yields an $R^{2}$ of .8 and .69 , respectively. We can also compute the solution of the differential equation for the Pareto distribution.
} 
where $W(z)$ is the Lambert $W$-function defined as the real solution of $z=x e^{x}$ for $x$.

Proposition 4 The assignment function $z(j ; \lambda)$ is continuously decreasing and convex in $j$ and $\lambda$. The cross-partial derivative $z_{j, \lambda}$ is negative for all $j<\bar{\jmath}(\lambda)$ and positive for $j>\bar{\jmath}(\lambda)$.

Lorenz Curve of World Output With a continuum of countries, the income share of country $j$ becomes $\mu(j) / \int \mu(j) d j$ in the equilibrium without unbundling and $-z^{\prime}(j)$ in the equilibrium with unbundling. Integrating these shares, we obtain the Lorenz curves in the equilibrium with and without unbundling

$$
\begin{aligned}
L(j)^{\text {without }} & =\int_{j}^{\infty} \lambda e^{-\lambda j} d j=e^{-\lambda j}, \\
L(j)^{\text {with }} & =\int_{j}^{\infty}-z^{\prime}(j) d j=z(j),
\end{aligned}
$$

where $z(j)$ is given by (26). Note that the ordering of countries in the Lorenz curve is descending in the country index $j$. That is, the Lorenz curve is zero for $j=\infty$ and one for $j=0$. Comparing the two Lorenz curves, we find that $L(j)^{\text {without }}>L(j)^{\text {with }}$ for all $j \in(0,1) .{ }^{26}$ Thus, the world distribution is more unequal with unbundling, as measured by the Lorenz curve.

To better understand how the world income distribution changes throughout its support, we next analyze the change in income shares country by country. Rewriting the change in income shares as a function of the equilibrium assignment of intermediates $j(z)$, (25), we obtain 27

$$
\Delta s(z)=z \lambda\left(\frac{1}{1-z}-e^{1-z}\right)
$$

The change in income share is negative for $z \in(0, \bar{z})$ and positive for $z \in(\bar{z}, 1] .{ }^{28}$ Thus, the income share declines in the countries assigned to the intermediates $z<\bar{z}$ and it increases in the rest. The next proposition characterizes the change in the world income distribution as a function of fundamentals, rather than the endogenous variable $z$.

Proposition 5 The change in the income share from the equilibrium without unbundling to the equilibrium with unbundling, $\Delta s(j)$, (i) is continuous in $j$, (ii) it is decreasing in $j$ for $j<j_{-}$and increasing thereafter, with $j_{-}=\lambda^{-1}(-3 W(3)-\ln (1-3 W(3)))$, (iii) it is

\footnotetext{
${ }^{26}$ To see this, rewrite the Lorenz curves in terms of the assignment $\mathrm{j}(\mathrm{z}),(25)$, so that $L(z)^{\text {without }}=z e^{1-z}$ and $L(z)^{\text {with }}=z$, and the result follows.

${ }^{27}$ To derive this expression note that $s^{\text {without }}(z)=\lambda e^{-\lambda\left(-\frac{1+\ln \left(z e^{-z}\right)}{\lambda}\right)}=\lambda z e^{1-z}$. In addition, to express the income share with unbundling, note that $s^{\text {with }}(j)=-\frac{d z}{d j} \Longleftrightarrow s^{\text {with }}(z)=-\frac{1}{\frac{d j}{d z}}$. Using that $\frac{d j}{d z}=-\frac{1-z}{\lambda z}$, we have that $s^{\text {with }}(z)=\frac{\lambda z}{1-z}$. The change in income share in terms of $j$ is $\Delta s_{j}=\frac{\lambda W(-\exp (-1-\lambda j))}{1+W(-\exp (-1-\lambda j))}-\lambda \exp (-\lambda j)$.

${ }^{28}$ To see this, note that $\Delta s(z)$ is continuous, increasing for $z \in(1-3 W(1 / 3), 1]$ and decreasing otherwise. Moreover, $\Delta s(0)=0, \frac{d \Delta s}{d z}(0)<0, \frac{d \Delta s}{d z}(1)=\infty$ and the result follows. Note too that $\Delta s(z)$ is convex for all $z$.
} 
Figure 3: Change in World Income Shares

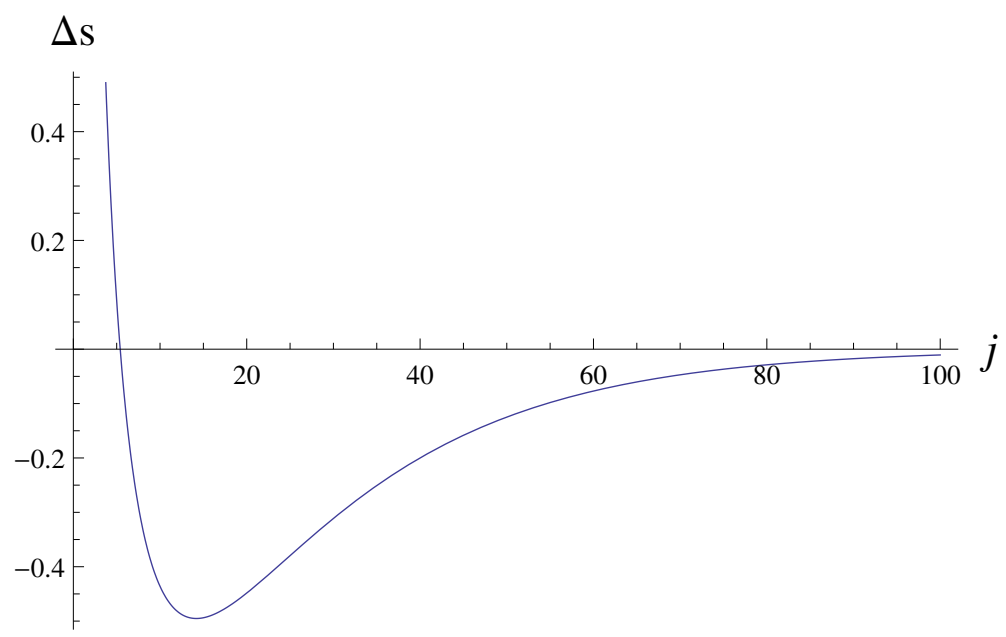

convex for $j<j_{c}$ and concave thereafter, with $j_{c}<j_{-}$, (iv) $\Delta s(0)=\infty, \Delta s(\infty)=0$ and $\Delta s\left(\lambda^{-1}(-W(1)-\ln (1-W(1)))\right)=0$.

This proposition implies that (i) top-bottom inequality increases with unbundling and (ii) the income share falls relatively more in middle-productivity countries. Figure 3 illustrates a generic case. Without unbundling of production, the demand of capital is determined by the number of varieties a country produces. In contrast, with unbundling, the demand of capital is determined by the intermediates in which the country specializes. The most productive country gains the most because it specializes in the most capital-intensive intermediates. Low productive countries specialize in low-capital-intensive intermediates but they do not lose much because they accumulated a small amount of capital in the equilibrium without unbundling. The main losers are middle-productivity countries. These countries accumulated a sizeable amount of capital in the equilibrium without unbundling. However, they now compete against more productive countries and end up specializing in relatively low-capitalintensive intermediates and, thus, with less capital and a lower income share. In other words, there is a large mismatch between the capital they accumulated in the equilibrium without unbundling and the needed to produce the equilibrium intermediates with unbundling.

Some of these predictions are in line with the observed changes in the world income distribution between 1990 and 2008. ${ }^{29}$ Consistent with our model, top-bottom income inequality increased during this period. For instance, the 90 th percentile to 10 th ratio of income per capita rose from 24 to 28 and the 95th-5th ratio went from 38 to 42 . To test the prediction that the income shares of most productive countries increases while they declined for the rest, we have regressed income per capita growth between 1990-2008 on the country's TFP ranking in 1988 from Hall and Jones (1999). We find that the coefficient of this regression

\footnotetext{
${ }^{29}$ We choose to finish at 2008 to exclude the effects of the Great Recession.
} 
is negative, which is supportive of our prediction. However, the coefficient is not precisely estimated and it is not significant at conventional levels. ${ }^{30}$ Indeed, many other factors have affected the world income distribution during this period and empirically disentangling the effects of unbundling on the world income distribution is beyond the scope of this paper.

World Output and Steady-State Welfare We can also compute the steady state levels of world output. To do so, we normalize the price of the final good to one and integrate the price index substituting in the equilibrium prices (see Online Appendix G.2 for the detailed derivations). We find that the expressions for world output in both steady-states

$$
\begin{aligned}
Y^{\text {World, without }} & =\frac{2}{e} \frac{\lambda}{\rho}, \\
Y^{\text {World, with }} & =\sqrt{e} \frac{\lambda}{\rho},
\end{aligned}
$$

where $e$ is the base of the natural logarithm, $e=2.718 \ldots$ Thus, we have that $Y^{\text {World, with }}>$ $Y$ World, without. This result is not surprising. Unbundling allows a more efficient usage of technologies in the world. Thus, world output increases with unbundling. This implies that there exists some countries whose share of the world income decreases with unbundling that enjoy higher steady-state welfare in the unbundling equilibrium. More precisely, we find that countries with $j \in\left[0, j_{+}\right)$increase their steady-state welfare in the unbundling equilibrium, while all countries with $j>j_{+}$decrease their steady state welfare. The threshold country has an index $j_{+}=\lambda^{-1}\left(-W\left(e^{3 / 2} / 2\right)-\ln \left(1-W\left(e^{3 / 2} / 2\right)\right)\right)$, which is strictly greater than the threshold country that increases its world income share $\lambda^{-1}(-W(1)-\ln (1-W(1)))$.

Within-country Inequality Finally, we analyze the changes in within-country inequality. The change in the Theil index in country $j$ is ${ }^{31}$

$$
\Delta T_{j}=(1-z) \ln (1-z)+z \ln z+\ln 2
$$

It implies that the change in inequality has a U-shape in the country index, with a minimum of zero at $j_{0}=\lambda^{-1}(\ln 2-1 / 2)$. Thus, within-country inequality generically increases with unbundling. The U-shape of $\Delta T_{j}$ implies that within-country inequality increases as the country index distances itself from $j_{0}$. In other words, the most and the least productive countries are the ones experiencing the highest increases in income inequality with unbundling. Indeed, it can be readily verified that $\Delta T_{j}$ is maximized for $j=\{0, \infty\}$. Finally, we note that

\footnotetext{
${ }^{30}$ Figure I.2 in the Online Appendix reports the distribution of the income per capita growth in this period over the TFP ranking of the countries.

${ }^{31}$ To compute the Theil index, note that the wage bill paid in country $j$ in the equilibrium with unbundling is $-z^{\prime}(j)(1-z(j)) Y$, total payments to capital are $-z^{\prime}(j) z(j) Y$ and the average between the two is $-z^{\prime}(j) Y / 2$. The Theil index for the equilibrium with unbundling is thus $\frac{1}{2}(2(1-z) \ln (2(1-z))+2 z \ln (2 z))$.
} 
the same U-shape result emerges when computing the Gini coefficient of each economy. The Gini coefficient is zero for country $j_{0}$, and it increases monotonically with $\left|j-j_{0}\right|{ }^{32}$

The U-shape prediction in the evolution of within-country inequality seems consistent with the data. We find that for developing countries, the change in the Gini coefficient between 1988 and 2008 is increasing in the TFP ranking of the country. ${ }^{33}$ The coefficient is $.09 \%$ and statistically significant at a $5 \%$ level, which means that moving from the 50 th to the 100th position in the ranking, increases the Gini coefficient in $4.5 \%$ points. Figure I.3a in the Online Appendix shows the scatter plot. For developed countries, we find that the relationship is reversed and, consistent with the prediction of the model, changes in the Gini coefficient are decreasing in the TFP ranking. However, the coefficient is not statistically different from zero at conventional levels. Figure I.3b in the Online Appendix shows graphically this relationship. One perhaps surprising feature of the TFP ranking by Hall and Jones is that Spain, Italy and France are more productive than the U.S., Canada, Germany or Netherlands. Indeed, as figure I.3b shows, these three countries are outliers in the regression. If we remove them, we obtain a negative and significant coefficient at a $5 \%$ level. Finally, we want to stress that many other factors such as taxation, technological change, etc. affect the income distribution of a country. While this evidence paints a picture consistent with our theoretical prediction, we do not attempt to identify the contribution of each different channel in this paper.

\section{Extensions}

In this section we make three extensions. The first extension studies the effects of southern countries joining the global supply chain. The second extension analyzes the effects of a labor saving technology, computerization, on inequality. In the last extension, we study how the diffusion of technology changes the world income distribution.

\subsection{South Joins the Global Supply Chain}

One interpretation of the increasing importance of trade in intermediates is that southern countries have joined the global supply chain (e.g., Baldwin, 2012). Figure 4 reports evidence supporting this view. It decomposes the ratio of exported intermediates to final goods be-

\footnotetext{
${ }^{32}$ The change in Theil index for the particular case of two heterogenous countries (which we omitted in the main text $)$ is $\Delta T_{1}=\frac{1}{2}\left(\left(1+z^{*}\right) \ln \left(1+z^{*}\right)+\left(1-z^{*}\right) \ln \left(1-z^{*}\right)\right)$ and $\Delta T_{2}=\frac{1}{2}\left(z^{*} \ln z^{*}+\left(2-z^{*}\right) \ln \left(2-z^{*}\right)\right)$. Note that within-country inequality increases in both countries. $\Delta T_{1}$ increases with $z$ and $\Delta T_{1}(z=0)=0$, thus, although the exact increase depends on the values of productivties $\theta_{1}$ and $\theta_{2}, \Delta T_{1}\left(z^{*}\right)>0$. Similarly, $\Delta T_{2}$ decreases with $z$ and $\Delta T_{2}(z=1)=0$, thus, $\Delta T_{2}\left(z^{*}\right)>0$.

${ }^{33}$ For data comparability, we need to distinguish between developing and developed countries. Gini coefficients for developing countries are obtained from the World Development Indicators (World Bank), which does not report time series for developed countries. For developed countries, we use Luxemburg Incomes Studies data. The threshold between developing and developed countries is the $50 \%$ of the U.S. per capita income in 1990. We use the TFP ranking from Hall and Jones (1999).
} 
Figure 4: Ratio of Value of Exported Intermediates to Final Goods.

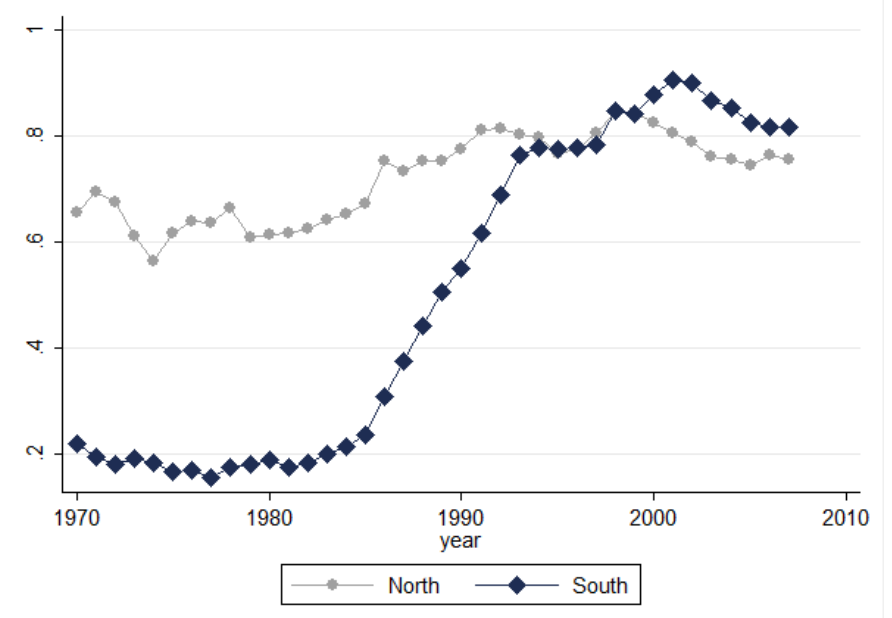

Source: Feenstra World Trade Database. To classify goods as intermediates, we use the enduse classification of Feenstra and Jensen (2012). Southern countries are defined as countries with GDP per capita (PPP) lower than 50 percent of the United States in 2000.

tween northern and southern countries. Note that trade in intermediates increased in both northern and southern countries after late 1980s but the most dramatic increase was in southern countries. For southern countries, the ratio was roughly constant around .2 before the 1990s, when it sharply increased and it has converged to around .8 in the late 2000s.

Motivated by this evidence, we analyze the effect on the world income distribution of southern countries joining the global supply chain. We consider a world of $J$ countries and define as South the set of countries with a productivity level $\theta$ below $\underline{\theta}$. We compare two equilibria. Before the South joins the global supply chain: all countries trade varieties but only countries with productivity $\theta$ above $\underline{\theta}$ can trade intermediates. After the South joins the global supply chain: all countries trade both varieties and intermediates.

The equilibrium after southern countries join the global supply chain is the same as in the baseline model (subsection 3.2.2). The income share of each country $j$ is given by $s_{j}^{a f t e r}=-d z^{a f t e r} / d j$, where the assignment of intermediates to countries is given by equation (26).

The equilibrium income share before the South joins the global supply chain is a piecewise function that specifies the income share for northern and southern countries separately. Southern countries are those with low productivity levels, that is, countries $j>\underline{j}$, where $\underline{j}$ $=\frac{1}{\lambda} \ln \left(\frac{\lambda}{\underline{\theta}}\right)$. As southern countries only trade varieties, their income shares, implied by the trade balance condition, are

$$
s_{j}^{\text {before }}=\theta(j)=\lambda \exp (-\lambda j), \quad \text { for } j>\underline{j} .
$$


Northern countries trade both varieties and intermediates. The trade balance of each northern country $j<\underline{j}$ implies that ${ }^{34}$

$$
s_{j}^{\text {before }}=-\frac{d z^{\text {before }}}{d j}\left(1-\frac{\int_{\underline{j}}^{\infty} \mu_{j} d j}{\int_{0}^{\infty} \mu_{j} d j}\right), \quad \text { for } j<\underline{j},
$$

where $z^{\text {before }}$ is the equilibrium assignment of intermediates when only northern countries trade intermediates.

Therefore, we need to derive the equilibrium assignment of intermediates to compute the income share of northern countries before the South joins the global supply chain. To derive the assignment, we proceed in an analogous way as in Section 3.2.2 and solve equation (24) with the terminal condition $z(\underline{j})=0$. That is, the South (countries with $j>\underline{j}$ ) does not participate in intermediates trade. The equilibrium assignment is given by

$$
j=-\frac{1-z^{\text {before }}}{\lambda}-\frac{C_{1}^{*}(\underline{j})}{\lambda^{2}} \ln \left(1-\frac{\lambda\left(1-z^{\text {before }}\right)}{C_{1}^{*}(\underline{j})}\right),
$$

where $C_{1}^{*}(\underline{j})$ is an integrating constant. We show in Online Appendix F.1 that $z^{\text {before }}(j ; j)$ is decreasing in $\underline{j}$. This is illustrated in Figure 5 a for two different $\underline{j}$. It means that if there are more countries participating in intermediates trade ( $j$ larger $)$, each northern country specializes in more capital-intensive intermediates (higher $z$ ). Finally, note that, by definition, $z^{\text {before }}(j ; \underline{j}=\infty)=z^{\text {after }}(j)$.

We can write the change in the world income distribution when the South joins the global supply chain as

$$
\Delta s_{j}= \begin{cases}-z^{\prime}(j)-\lambda e^{-\lambda j} & \text { if } j>\underline{j} \text { (Southern country), } \\ -z^{\prime}(j)+z^{\prime}(j ; \underline{j})\left(1-e^{-\lambda \underline{j}}\right) & \text { if } j<\underline{j} \text { (Northern country). }\end{cases}
$$

Proposition 6 When the South joins the global supply chain, all northern countries increase their income shares. If $\underline{j}<j^{*}$, southern countries with $j \in\left[j, j^{*}\right]$ increase their income share and the rest decrease their share, where $j^{*}=-\lambda^{-1}\left(W(1)+\ln (1-W(1))\right.$. If $\underline{j}>j^{*}$, the income share of all southern countries declines.

The reason for these results is as follows. For southern countries, we have the same comparison as in Section 3.2.2. Their income shares increase if they can produce more in-

\footnotetext{
${ }^{34}$ Denoting by $\xi_{j}$ the amount of varieties produced by southern countries (i.e., $\xi_{\underline{j}}=\sum_{j=\underline{j}}^{J} \mu_{j}$ ), the trade balance of northern countries $j$ becomes

$$
\frac{\mu_{j}}{N}\left(\sum_{i=1}^{J} p_{i} Y_{i}-p_{j} Y_{j}\right)+Z_{j} \frac{N-\xi_{\underline{j}}-\mu_{j}}{N} \sum_{i=1}^{J} p_{i} Y_{i}=\frac{N-\mu_{j}}{N} p_{j} Y_{j}+\left(1-Z_{j}\right) \frac{\mu_{j}}{N} \sum_{i=1}^{J} p_{i} Y_{i}
$$

Rearranging, $s_{j}^{\text {before }}=Z_{j}^{\text {before }}\left(1-\frac{\xi_{j}}{N}\right)$ and taking the limit to a continuum of countries becomes (28).
} 
Figure 5: South joins the Gobal Supply Chain

(a) Change in Equilibrium Assignment with $j$

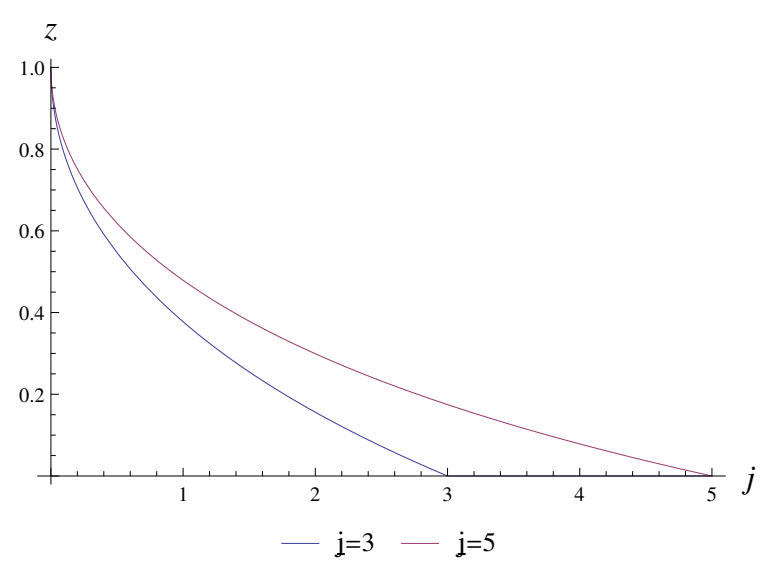

(b) Change in the World Income Distribution

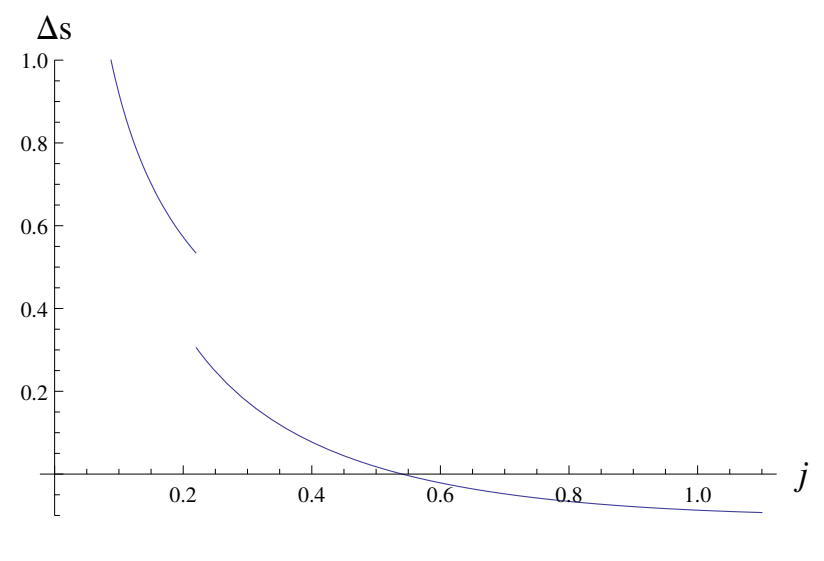

termediates than their share of varieties. Therefore, if the country is productive enough, it produces enough intermediates and accumulates more capital participating in the global supply chain, thereby increasing its income share. For northern countries, there are two effects: (i) selection effect: they produce less intermediates but they are more capital-intensive and (ii) market size effect: northern countries sell intermediates to all the countries, not only in the North. The overall effect is positive because northern countries specialize in more capitalintensive intermediates and sell them to a bigger market. Figure 5b illustrates the change in the world income distribution.

In this section, we have assumed, for simplicity, that southern countries either fully participated or did not participate in intermediates trade. In Section $\mathrm{H}$ of the Online Appendix we relax this assumption and we assume that a fraction $\alpha(j)$ of a country participates in intermediates trade, where $\alpha(j)$ is a decreasing function of $j$. We show numerically that the same qualitative results hold. As $\alpha(j)$ increases, the income share increases in countries with $j<j^{*}$ and it decreases in the rest.

\subsection{Computerization}

The adoption of Information Technologies has been pointed out as one important reason behind the unbundling of production (see, for example, Basco and Mestieri, 2013). Moreover, Autor et al. (2003) among others have argued that computerization, by eliminating laborintensive tasks, has also changed the income distribution within countries. In this extension, we analyze how the effects of computerization on the income distribution depend on the trade regime.

As discussed in equation (5), a bundle of intermediates of different labor-intensity must 
be assembled to produce a variety $v$,

$$
x_{j}(v)=\exp \left[\int_{0}^{1} \beta(z) \ln a_{j}(z, v) d z\right]
$$

where $\beta(z)$ is a weight on intermediate $z$, with $\int_{0}^{1} \beta(z) d z=1$. We model computerization as a shift in the weighting function $\beta(z)$ that reduces the weight of labor-intensive (low $z$ ) intermediates.

More precisely, we assume that the distribution $\beta(z)$ has a monotonically decreasing probability ratio (MPR), where the probability ratio is defined as

$$
\mathcal{I}(z)=\frac{\beta(z)}{B(z)}
$$

and $B(z)$ denotes the cumulative distribution of $z \cdot{ }^{35}$ We assume that computerization induces a shift in $\beta(z)$ that can be ranked in terms of the probability ratio. Supposing that $\gamma$ indexes computerization, we assume that $\mathcal{I}(z ; \gamma)$ is monotonically increasing in $\gamma$. Eeckhoudt and Gollier (1995) show that a monotone increase in the probability ratio implies a first-order stochastic dominant shift. ${ }^{36}$ Accordingly, we define computerization as an increase in $\gamma$. That is, an increase in $\gamma$ implies that, ceteris paribus, less relatively labor-intensive intermediates are needed to produce each variety.

For example, one family of distributions satisfying the MPR ordering is given by

$$
\beta(z)= \begin{cases}0 & \text { if } z<\gamma \\ \frac{1}{1-\gamma} & \text { if } z \in[\gamma, 1]\end{cases}
$$

where $\gamma$ is the index of computerization. When $\gamma=0$, there is no computerization and $\beta(z)=$ 1 , as we assumed in the baseline model. For $\gamma>0$, the most labor-intensive intermediates $z<\gamma$ are no longer required to produce varieties.

In the equilibrium without unbundling, the income share of each country depends only on the number of varieties and it is given by $s_{j}=\mu_{j} / \int_{j \in \mathcal{J}} \mu_{j} d j$, which is independent on the weighting function $\beta(z)$. However, computerization decreases the demand of labor, which in equilibrium increases the capital income share.

To analyze the equilibrium with unbundling, note that computerization changes the equilibrium assignment. Proceeding as in section 3.2.2, the assignment function is characterized

\footnotetext{
${ }^{35}$ This condition has been applied in other economic contexts, see Hopkins and Kornienko (2004) and the references therein. The normal, uniform and exponential distribution among other distributions satisfy this condition.

${ }^{36}$ Moreover, they also show that a Monotone Likelihood Ratio (MLRP) order implies MPR. Thus, MPR is more stringent than first-order stochastic dominance but less stringent than MLRP.
} 
by the following differential equation

$$
(1-z(j))\left(\frac{z^{\prime \prime}(j)}{z^{\prime}(j)}+z^{\prime}(j) \frac{\beta^{\prime}(z(j))}{\beta(z(j))}\right)-z^{\prime}(j)=\frac{\theta^{\prime}(j)}{\theta(j)}=-\lambda .
$$

Note that $\beta(z)$ enters into the assignment function through its semi-elasticity, $z^{\prime}(j) \beta^{\prime}(z) / \beta(z)$.

The solution to this differential equation with boundary conditions $z(0)=1$ and $z(\infty)=0$ is given $b^{37}$

$$
j(z)=\frac{1}{\lambda} \int_{z}^{1} \mathcal{I}(x, \gamma)(1-x) d x .
$$

The income share in terms of $z$ is

$$
s(z)=\frac{\lambda}{\mathcal{I}(z, \gamma)(1-z)}
$$

With unbundling, computerization changes the world income distribution. From equation (30), we see that $\gamma$ affects the income shares through the inverse probability ratio, $\mathcal{I}(z, \gamma)$, and the equilibrium assignment $z(j(\gamma))$. On the one hand, by assumption, $\mathcal{I}(z, \gamma)$ is increasing in $\gamma$, which reduces the income share. On the other hand, $z(j(\gamma))$ increases with $\gamma$, each country $j$ is now assigned to a higher $z$ intermediate, which raises the income share. ${ }^{38}$ Therefore, the overall effect on the income share (30) is ambiguous. The next Proposition shows that it depends on the country ranking.

Proposition 7 In the equilibrium without unbundling, computerization does not affect inequality between countries. In the equilibrium with unbundling, computerization increases the income share for countries with $j \in\left[0, j_{1}\right)$ and decreases it for countries with $j>j_{2}$. If $\beta(z)$ is given by equation (29), an increase in $\gamma$ increases the income share of countries $j<j^{*}$, while it decreases in the rest. Computerization raises the capital income share in all countries and both trade regimes.

Proposition 7 implies that top-bottom inequality unambiguously increases. The reason is that all countries specialize in more capital-intensive intermediates. However, this shift in the pattern of specializing disproportionately favors the most productive countries, which can now specialize in even more capital-intensive intermediates. This is the reason why the income share raises at the top. The least productive countries do not benefit from computerization because $\beta(z)$ does not change much at the extreme of the distribution.

To sum up, in this section we have shown that the effects of computerization on the world income distribution depend on the trade regime. Without unbundling, computerization does

\footnotetext{
${ }^{37}$ Note that if $\beta(z)=1$, we obtain that $j(z)=\lambda^{-1}(z-\ln z-1)$ as in the baseline model. Also, note that, for simplicity, we are reporting the case in which the support of intermediates remains $[0,1]$. Online Appendix F.2 discusses the case when $\beta(z)$ takes the form of (29), in which the support changes with computerization.

${ }^{38}$ Note from equation $(4.2)$ that $j(z, \gamma)$ increases monotonically with an increase in $\mathcal{I}(z, \gamma)$.
} 
not change the relative income of countries. In contrast, with unbundling, computerization leads all countries to specialize in more capital-intensive intermediates, which exacerbates the income differences between countries. Moreover, computerization always raises the capital income share. This empirical prediction is consistent with the finding of Karabarbounis and Neiman (2013) that the labor-share has declined in most countries.

\subsection{Diffusion of technology}

The source of comparative advantage in our model is technology. In the baseline model we assumed that technology is exogenous and constant. However, technology diffuses over time and low-productivity countries eventually learn the innovations that the countries in the technological frontier make. In this section we analyze how the diffusion of technology changes the world income distribution with and without unbundling.

We assumed, consistent with the data, that productivity follows an exponential distribution

$$
\theta(j)=\lambda \exp (-\lambda j)
$$

We model technological catch-up of low-productivity countries as a decline in the parameter $\lambda$ from $\lambda_{1}$ to $\lambda_{2}<\lambda_{1}$. This implies a first-order stochastic shift in the distribution of productivities in the world. ${ }^{39}$

Proposition 8 Diffusion of technology leads to convergence in income with and without unbundling. Moreover, the income share increases in more low-productivity countries when there is unbundling of production.

These results are illustrated in Figure 6. Without unbundling of production, the income share of country $j$ is $s_{j}^{\text {without }}=\theta(j)$. Note that changes in productivity directly affect the income share. It is then straightforward to see that the income share increases in lowproductivity countries $(j>\bar{j})$ and declines in the rest $(j<\bar{j}) \cdot{ }^{40}$ Therefore, diffusion of technology leads to convergence in income shares.

With unbundling of production, the income share of country $j$ is $s_{j}^{w i t h}=-z^{\prime}(j)$. It means that productivity affects the income share through the endogenous assignment of intermediates. To understand the effect of technology diffusion on the income share, first notice how

\footnotetext{
${ }^{39}$ Note that this formulation implies a counterfactual decline in the TFP level of the most productive countries. We choose this formulation for notational convenience. It can be verified that the same results on income shares apply if we define technological catch-up as a change only in the slope of the original exponential function, $\theta(j)=\lambda \exp (-(\lambda-\xi) j)$ with $\xi>0$. This formulation would avoid reducing TFP in absolute levels for the most productive countries. However, the same results go through in terms of income shares because, in relative terms, we still have a decline in TFP for the most productive countries and the assignment function would remains unaltered as $\theta^{\prime}(j) / \theta(j)=-\lambda+\xi$.

${ }^{40}$ Using that $\theta(j)$ follows an exponential distribution, the threshold $\bar{j}$ is $\bar{j}=\frac{\ln \left(\frac{\lambda_{1}}{\lambda_{2}}\right)}{\lambda_{1}-\lambda_{2}}$.
} 
the assignment function changes,

$$
\Delta j=\left(\frac{1}{\lambda_{2}}-\frac{1}{\lambda_{1}}\right)(z-\ln z-1)>0 .
$$

This change in the assignment function implies that low-productivity countries are climbing up the ladder of global supply chains by producing higher $z$ intermediates. This new selection of intermediates results in an increase in the income share of low-productivity countries $\left(j>j^{\dagger}\right)$ and a decline in the rest $\left(j<j^{\dagger}\right)$. The reason is that, due to the diffusion of technology, lowproductivity countries can now produce more intermediates, thereby increasing their income share. This result implies that diffusion of technology leads to income convergence.

Finally, we compare the changes in the world income distribution under the two trade regimes. It is straightforward to check that

$$
\left.\frac{\partial s_{j}^{w i t h}}{\partial \lambda}\right|_{j=\bar{j}}<0 .
$$

This inequality implies that $\bar{j}>j^{\dagger}$, which means that in the equilibrium with unbundling the income share increases for a larger mass of low-productivity countries. In particular, the income share of countries with $j \in\left(j^{\dagger}, \bar{j}\right)$ raises with unbundling but falls without unbundling. The intuition is that, in the equilibrium with unbundling, the relative productivity (not the absolute level) determines the assignment of intermediates. The slope of the distribution of productivities flattens with the diffusion of technology, which results in countries with productivity $j \in\left(j^{\dagger}, \bar{j}\right)$ gaining comparative advantage against nearby more-productive countries, which allows them to climb the supply chain ladder and produce relatively more capital-intensive intermediates.

To sum up, in this section we have shown that diffusion of technology leads to convergence in income under the two trade regimes. However, the mass of low-productivity countries benefiting from technological catch-up is larger in the trade equilibrium with unbundling.

\section{Concluding Remarks}

In this paper we have developed a framework to study how the international unbundling of production changes the world income distribution. In our setup, countries only differ in their productivity. Each variety requires a bundle of intermediates, which use capital and labor in different proportions.

We showed that in the steady-state without unbundling (only varieties are costlessly traded), the world income share is determined by the fraction of varieties that each country produces. This world income distribution changes with unbundling (intermediates can also be traded). The world income share of a country depends on the intermediates in which 
Figure 6: Change in the World Income Distribution with a change in $\lambda$

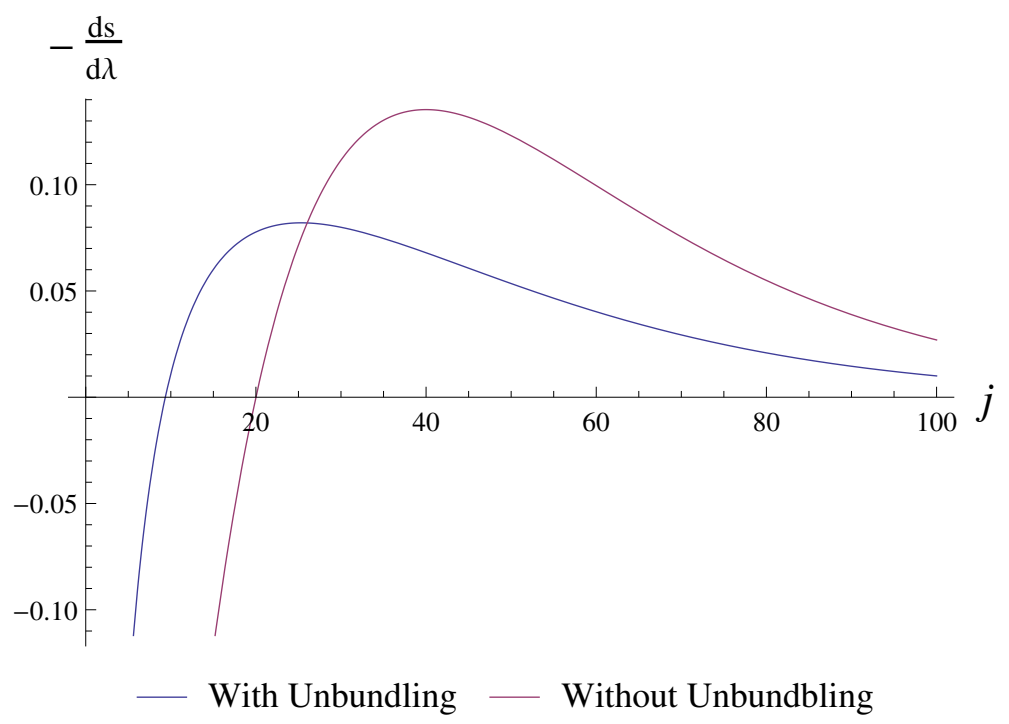

each country specializes.

Our first main result is that unbundling of production brings about symmetry breaking. That is, countries with the same productivity have the same income in the equilibrium without unbundling. In contrast, unbundling of production leads to divergence in income levels. The intuition is that arbitrarily small differences in productivity translate into comparative advantage differences in capital-intensive intermediates. Specialization in capital-intensive intermediates, induces capital accumulation, thereby reinforcing the initial comparative advantage. As a result, specialization in capital-intensive intermediates increases the capital-labor ratio of a country, which translates into a higher income share. We also show that within-country inequality emerges with unbundling.

Our second main result is to show that unbundling of production raises top-bottom inequality and it generates non-monotonic changes in the world income distribution. The largest fall in income shares is in middle-productivity countries. The reason is that the most productive countries specialize in capital-intensive intermediates and, thus, accumulate more capital and become relatively richer. Middle-productivity countries lose relatively more because they produce a sizeable amount of varieties and, thus, they accumulated a considerable amount of capital in the equilibrium without unbundling. However, with unbundling, the stock of capital only depends on the intermediates in which the country specializes. Since the country has intermediate productivity, it specializes in relatively low-capital-intensive intermediates. Thus, it accumulates relatively less capital and it ends with a lower income share. Within-country inequality also increases in our set-up.

We showed that when southern countries join the global supply chain (participate in 
trade in intermediates), the income shares of all northern and the most productive southern countries increase, while they decrease for the rest of southern countries. The reason is that northern countries specialize in more capital-intensive intermediates and sell them to a larger market. However, only productive enough southern countries are able to climb up the ladder of global supply chains to specialize in sufficiently capital-intensive intermediates.

We also analyze how the effect of a labor-saving technology, computerization, depends on the trade regime. Without unbundling, computerization has no effect on the world income distribution. In contrast, with unbundling, computerization exacerbates inequality between countries. The reason is that with computerization all countries specialize in more capitalintensive intermediates, which disproportionately favors the most productive countries.

Finally, our model predicts that diffusion of technology leads to income convergence. However, the mass of countries benefiting from technological catch-up is larger in the trade equilibrium with unbundling of production. The reason is that in these countries relative productivity declines, which reduces the income share without unbundling. However, relative productivity falls less than in their nearby more-productive countries, which allows them to produce more capital-intensive intermediates and increase their income share with unbundling.

The unbundling of production is exogenous in the model. Nonetheless, in practice, firms adopt technologies (for example, computers and the internet) to be able to offshore part of the production process. We plan on extending our framework to analyze the interdependence between technology adoption and trade. We have only considered two factors of production: capital and labor. Although we think of capital in broad terms, which could also include human capital (along the lines of Matsuyama, 2004), a more careful investigation of the distinctive effects of human capital accumulation would be another interesting extension of the model. Lastly, in our baseline model, we assume that intermediates are either costelessly traded or non-traded. Online Appendix D shows that our framework can be extended to have an arbitrary fraction of intermediates being traded. In future work, we intend to quantitatively investigate the effects of changes in the fraction of intermediates traded on different long-run and short-run trade elasticities. 


\section{References}

Acemoglu, D. And J. Ventura (2002): "The World Income Distribution," The Quarterly Journal of Economics, 117, 659-694.

Antràs, P. (2014): Global Production: A Contracting Perspective, Book Manuscript.

Antràs, P. And D. Chor (2013): "Organizing the Global Value Chain," Econometrica, Econometric Society, 81, 2127-2204.

Autor, D. H., F. Levy, And R. J. Murnane (2003): "The Skill Content Of Recent Technological Change: An Empirical Exploration," The Quarterly Journal of Economics, 118, 1279-1333.

Bajona, C. And T. Kehoe (2010): "Trade, Growth, and Convergence in a Dynamic Heckscher-Ohlin Model," Review of Economic Dynamics, 13, 487-513.

BALDwin, R. (2012): "Global supply chains: Why they emerged, why they matter, and where they are going," CEPR Discussion Papers 9103, C.E.P.R. Discussion Papers.

Baldwin, R. And F. RoberT-Nicoud (2014): "Trade-in-goods and trade-in-tasks: An integrating framework," Journal of International Economics, 92, 51-62.

Baldwin, R. AND A. J. Venables (2013): "Spiders and snakes: Offshoring and agglomeration in the global economy," Journal of International Economics, 90, 245-254.

Basco, S. And M. Mestieri (2013): "Heterogeneous Trade Costs and Wage Inequality: A Model of Two Globalizations," Journal of International Economics, 89, 393-406.

Baxter, M. (1992): "Fiscal Policy, Specialization, and Trade in the Two-Sector Model: The Return of Ricardo?" Journal of Political Economy, University of Chicago Press, 100, 713-44.

BaXter, M. And M. A. Kouparitsas (2003): "Trade Structure, Industrial Structure, and International Business Cycles," American Economic Review, 93, 51-56.

Bernard, A. B., J. B. Jensen, And P. K. Schott (2006): "Survival of the best fit: Exposure to low-wage countries and the (uneven) growth of U.S. manufacturing plants," Journal of International Economics, 68, 219-237.

Caliendo, L. (2011): "On the Dynamics of Heckscher-Ohlin Theory," Mimeo.

Caliendo, L. And F. Parro (2012): "Estimates of the Trade and Welfare Effects of NAFTA," NBER Working Papers 18508, National Bureau of Economic Research, Inc.

Costinot, A. And J. Vogel (2010): "Matching and Inequality in the World Economy," Journal of Political Economy, 118, 747-786.

Costinot, A., J. Vogel, And S. Wang (2013): "An Elementary Theory of Global Supply Chains," Review of Economic Studies, 80, 109-144.

Cunat, A. And M. Maffezzoli (2004): "Neoclassical Growth and Commodity Trade," Review of Economic Dynamics, 7, 707-736.

Davis, D. R. And D. E. Weinstein (2001): "An Account of Global Factor Trade," American Economic Review, 91, 1423-1453.

Deardorff, A. (1998): "Fragmentation Across Cones," Papers, Michigan - Center for Research on Economic \& Social Theory 98-14, Michigan - Center for Research on Economic \& Social Theory. 
DeardorfF, A. V. (2001a): "Fragmentation in simple trade models," The North American Journal of Economics and Finance, 12, 121-137.

(2001b): "Rich and Poor Countries in Neoclassical Trade and Growth," Economic Journal, $111,277-94$.

Dedrick, J., K. L. Kraemer, And G. Linden (2010): "Who profits from innovation in global value chains?: a study of the iPod and notebook PCs," Industrial and Corporate Change, 19, 81-116.

Eaton, J. And S. KorTum (2002): “Technology, Geography, and Trade," Econometrica, Econometric Society, 70, 1741-1779.

Eeckhoudt, L. And C. Gollier (1995): "Demand for Risky Assets and the Monotone Probability Ratio Order," Journal of Risk and Uncertainty, 11, 113-22.

EthieR, W. J. (1984): "Higher dimensional issues in trade theory," in Handbook of International Economics, ed. by R. W. Jones and P. B. Kenen, Elsevier, vol. 1, chap. 03, 131-184, 1 ed.

Feenstra, R. C. And J. B. Jensen (2012): "Evaluating Estimates of Materials Offshoring from US Manufacturing," Economics Letters, 117, 170-173.

Grossman, G. M. and E. Helpman (1993): Innovation and Growth in the Global Economy, vol. 1 of MIT Press Books, The MIT Press.

Grossman, G. M. and E. Rossi-Hansberg (2008): "Trading Tasks: A Simple Theory of Offshoring," American Economic Review, 98, 1978-97.

Hall, R. E. And C. I. Jones (1999): "Why Do Some Countries Produce So Much More Output Per Worker Than Others?" The Quarterly Journal of Economics, 114, 83-116.

Hanson, G. H. (2012): "The Rise of Middle Kingdoms: Emerging Economies in Global Trade," Journal of Economic Perspectives, 26, 41-64.

Hanson, G. H., R. J. Mataloni, and M. J. Slaughter (2005): "Vertical Production Networks in Multinational Firms," The Review of Economics and Statistics, 87, 664-678.

Hopkins, E. And T. Kornienko (2004): "Ratio Orderings and Comparative Statics," ESE Discussion Papers 91, Edinburgh School of Economics, University of Edinburgh.

Hummels, D., J. IshiI, AND K.-M. Yi (2001): "The Nature and Growth of Vertical Specialization in World Trade," Journal of International Economics, Elsevier, 54, 75-96.

Johnson, R. C. (2014): "Five Facts about Value-Added Exports and Implications for Macroeconomics and Trade Research," Journal of Economic Perspectives, 28, 119-42.

Karabarbounis, L. And B. Neiman (2013): "The Global Decline of the Labor Share," The Quarterly Journal of Economics, 129, 61-103.

Kohler, W. (2004): "International Outsourcing and Factor Prices with Multistage Production," The Economic Journal, 114, C166-C185.

Krugman, P. R. And A. J. Venables (1995): "Globalization and the Inequality of Nations," The Quarterly Journal of Economics, 110, 857-80.

Matsuyama, K. (2004): "Financial Market Globalization, Symmetry-Breaking, and Endogenous Inequality of Nations," Econometrica, 72, 853-884. 
(2013): "Endogenous Ranking and Equilibrium Lorenz Curve Across (ex ante) Identical Countries," Econometrica, 81, 2009-2031.

Rodríguez-Clare, A. (2010): "Offshoring in a Ricardian World," American Economic Journal: Macroeconomics, 2, 227-58.

Romalis, J. (2004): "Factor Proportions and the Structure of Commodity Trade," American Economic Review, 94, 67-97.

Sснотт, P. K. (2003a): "A Comparison of Latin American and Asian Product Exports to the United States, 1972 to 1999," Latin American Journal of Economics, 40, 414-422.

—_ (2003b): "One Size Fits All? Heckscher-Ohlin Specialization in Global Production," American Economic Review, 93, 686-708.

— (2004): "Across-product Versus Within-product Specialization in International Trade," The Quarterly Journal of Economics, 119, 646-677.

Ventura, J. (1997): "Growth and Interdependence," The Quarterly Journal of Economics, 112, $57-84$.

(2005): "A Global View of Economic Growth," in Handbook of Economic Growth, ed. by P. Aghion and S. Durlauf, Elsevier, vol. 1 of Handbook of Economic Growth, chap. 22, 1419-1497.

YI, K.-M. (2003): "Can Vertical Specialization Explain the Growth of World Trade?" Journal of Political Economy, 111, 52-102.

\section{A Tables and Figures}

Table 1: TFP and Exports in Labor-Intensive Industries

\begin{tabular}{lccccc}
\multicolumn{5}{c}{$X_{i c t}=\alpha+\beta \cdot \mathrm{TFP}_{c} \cdot$ Capital Intensity } \\
& $(1)$ & $(2)$ & $(3)$ & $(4)$ & $(5)$ \\
\hline TFP $_{c} \cdot$ Capital-Intensity $_{i}+\delta_{i t}+\varepsilon_{i c t}$ & 0.88 & 1.82 & 1.82 & 2.77 & 2.75 \\
& $(0.26)$ & $(0.41)$ & $(0.41)$ & $(0.62)$ & $(0.62)$ \\
\hline Country Fixed Effects & Yes & Yes & Yes & Yes & Yes \\
Year Fixed Effects & Yes & Yes & Yes & Yes & Yes \\
NAICS3 Fixed Effects & Yes & No & No & No & No \\
NAICS6 Fixed Effects & No & Yes & Yes & Yes & Yes \\
Year*Country FE & No & No & Yes & No & Yes \\
Year*NAICS6 FE & No & No & No & Yes & Yes \\
Observations & 207,320 & 207,320 & 207,320 & 207,320 & 207,320 \\
\hline
\end{tabular}

Notes: Standard errors are clustered at country level. $X_{i c t}$ is the log of world exports of intermediates $i$ of country $c$ in year $t$ from 1994 to 2008. Our data is disaggregated at 6-digit NAICS. We classify intermediates using Feenstra and Jensen (2012) classification. TFP is from Hall and Jones (1999) in 1988. Capital-intensity is measured as capital shares, which are computed from the NBER CES manufacturing industry database following their definition: $\alpha_{k}=1-\sum_{i \in \mathcal{I}} \alpha_{i}$, where $\mathcal{I}$ denotes production workers, non-production workers, energy and materials. Our data stops in 1994 because prior to this year we do not have the same level of disaggregation. 
Figure 7: Distribution of Capital-Intensity for Intermediates and Varieties

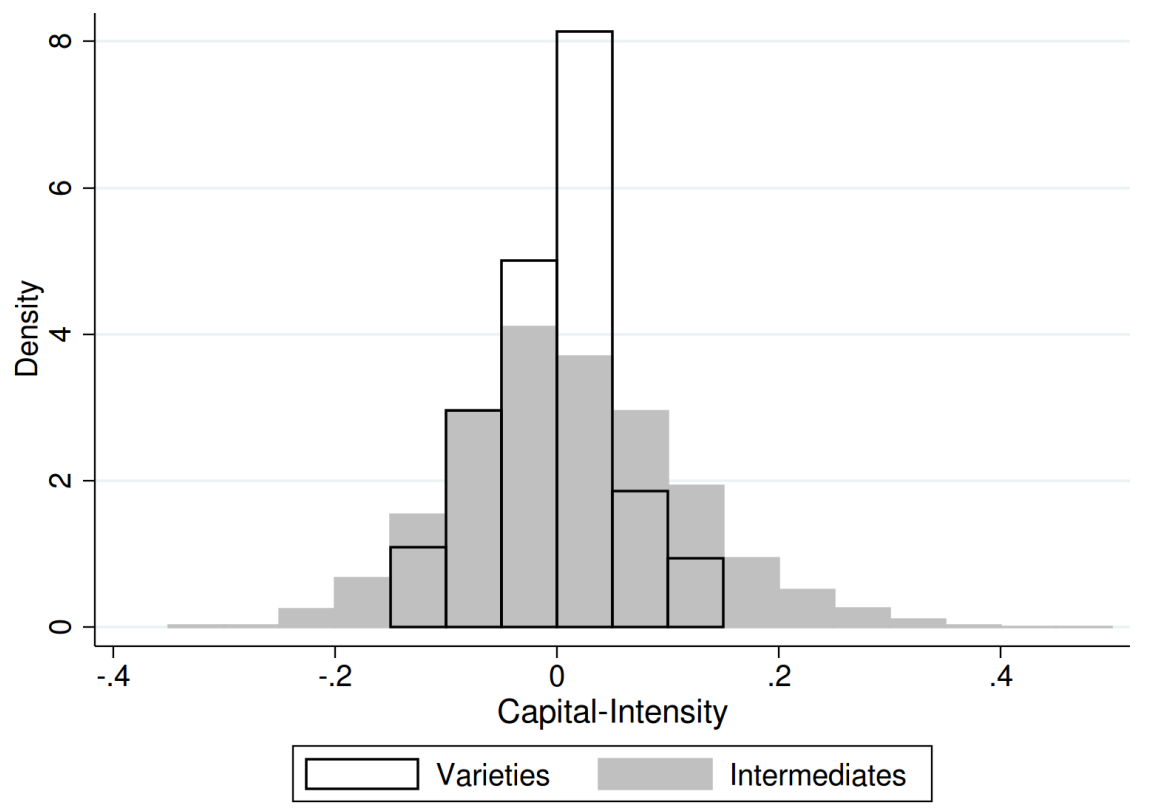

Notes: We define variety as a 3-digit NAICS and intermediate as a 6-digit NAICS (the highest level of disaggregation available). To construct the histograms we compute demeaned measures of capital-intensity. Capital-intensity of a variety is the difference between the weighted average of the capital shares of the intermediates used to produce the variety and the capital share of the average variety. Similarly, capital-intensity of an intermediate is the difference between the capital share of the intermediate and the capital share of the variety that uses the intermediate. Capital shares of intermediates are computed from the NBER CES manufacturing industry database following their definition. We use the 1997 direct requirement U.S. Input-Output tables from the BEA to impute the weight of each intermediate in the production of each variety. We report the results for year 1990 (the year around which we assume the unbundling of production started). We obtain the same qualitative results for year 2000. Table A.1 in the Online Appendix provides additional measures of capital-intensity dispersion (standard deviation, interquartile range and range). 